\title{
Displaywide visual features associated with a search display's appearance can mediate attentional capture
}

\author{
BRYAN R. BURNHAM \\ University at Albany, State University of New York, Albany, New York
}

\begin{abstract}
Whether or not the capture of visual attention is driven solely by the salience of an attention-capturing stimulus or mediated by top-down control has been a point of contention since Folk, Remington, and Johnston (1992) introduced their contingent involuntary orienting hypothesis, which states that the capture of attention by a salient stimulus depends on its relevance to a feature distinguishing the target from nontargets. Gibson and Kelsey (1998) extended Folk et al.'s (1992) hypothesis by demonstrating that features associated with the appearance of the target display also mediate capture. Although similar to Folk et al. (1992), Gibson and Kelsey's displaywide contingent orienting hypothesis makes it difficult to demonstrate stimulus-driven capture, because an observer must always use some perceptible feature as a signal of the target display's appearance; hence, such features could always be mediating capture. The present article reviews and applies the logic of Gibson and Kelsey's and Folk et al.'s (1992) hypotheses to experiments from the attentional capture literature, and assesses whether previously reported capture effects were mediated by top-down attentional control. It concludes that these capture effects were not stimulus-driven.
\end{abstract}

Extensive research has demonstrated that a salient visual stimulus (cue or distractor) can cause shifts in a person's attention toward its location. This can result in faster response times (RTs) and greater response accuracy to targets presented at the same location rather than at some other location, as long as the target appears shortly after the cue's onset (e.g., Folk, Remington, \& Johnston, 1992; Jonides, 1981; Jonides \& Yantis, 1988; Posner, 1980; Posner \& Cohen, 1984; Posner, Snyder, \& Davidson, 1980; Theeuwes, 1992, 1994, 2004; J. T. Todd \& Van Gelder, 1979; Yantis \& Egeth, 1999; Yantis \& Jonides, 1984). A faster RT to a target presented nearer to the location of a salient cue than to another location is an attentional capture effect.

The logic underlying attentional capture is as follows: If a cue draws attention to its location, and a target appears in that same (cued) location, observers will respond quickly and accurately, because their attention is already at the target's location. In contrast, if the target appears at some other (uncued) location, an observer must reshift attention from the cued location to locate the target; this slows RTs (Posner, 1980; Yantis, 1996, 1998, 2000).

Many forms of visual salience have been used to elicit capture but represent variations within one of two dimensions. The dynamic dimension includes stimuli made salient due to a change over time (Lamy \& Egeth, 2003), such as the abrupt onset or offset of an item (Jonides, 1981; Theeuwes, 1991b; Yantis \& Jonides, 1984), the increase or decrease of an item's luminance (Rauschenberger, 2003b), or the initiation of motion (Abrams \& Christ, 2003). The static dimension includes items made salient due to a change over space between simultaneously presented items (Lamy \& Egeth, 2003) such as a red item among green items (Theeuwes, 1992), a square among circles (Theeuwes, 1992), or a bright or dim item among dim or bright items, respectively (Rauschenberger, 2003b).

One might believe that each of these stimuli would capture attention, because each stands out from its background. However, a debate in the literature has focused on the extent to which bottom-up and top-down mechanisms mediate attentional capture. Some propose that salient stimuli cause attentional shifts toward their locations in a bottom-up (stimulus-driven) manner; that is, salient events (especially the onset of an item, or a luminance change) are assigned high attentional priority and automatically capture attention on the basis of physical salience alone (e.g., Jonides, 1981; Jonides \& Yantis, 1988; Theeuwes, 1991a, 1992, 1994, 2004; Yantis, 1993, 2000; Yantis \& Jonides, 1984 ). In contrast, others contend that attention is captured by salient stimuli relevant to a person's task demands, and that attention is withheld from - that is, precluded from shifting to - salient but irrelevant stimuli (e.g., Ansorge \& Heumann, 2003; Bacon \& Egeth, 1994; Folk \& Remington, 1999; Folk, Remington, \& Johnston, 1992, 1993; Folk, Remington, \& Wright, 1994; Gibson \& Kelsey, 1998; Lamy, Leber, \& Egeth, 2004). That is, capture is contingent on the features of a salient stimulus being similar to some task-relevant feature.

In this article, I review the attentional capture literature and determine the extent to which previously reported cap-

B. R. Burnham, attention.perform@gmail.com 
ture effects can be explained by top-down mediation. This review differs from previous reviews by Yantis (1996, 1998, 2000) and Theeuwes, Atchley, and Kramer (2000) that discuss empirical findings and the mechanisms assumed to underlie capture. The review also differs from Rauschenberger's (2003a) review of methods used in attentional capture research, which resulted in his creation of a new taxonomy of the paradigms used in this area of research. This review also differs from Simons's (2000) review, which discussed the similarity between (and ecological validity of) attentional capture by salient but irrelevant stimuli and inattentional blindness to salient but potentially relevant stimuli. In my article, I show how a too-often overlooked top-down hypothesis put forth by Gibson and Kelsey (1998) can account for capture effects, whereas other top-down theories cannot do so. This review also will show that there is no compelling evidence for stimulus-driven capture. Before I describe Gibson and Kelsey's hypothesis, I will introduce the three main paradigms used to investigate attentional capture.

\section{Attentional Capture Paradigms}

There are three main procedural dimensions in which attentional capture experiments vary. (For similar reasoning but with two dimensions, see Rauschenberger, 2003a.) First, a cue can precede a target or be presented simultaneously with it. Second, the target can be localized by a unique feature, or be indistinguishable from nontargets. Finally, the cue and target can sometimes (or always) appear in the same location, or never occur in the same location. However, not every one of the eight cells created by the factorial combination of these three dimensions applies to each paradigm.

\section{Spatial Precuing Paradigm}

The spatial precuing paradigm involves the presentation of a cue prior to the appearance of a target. For example, Jonides (1981; see Figure 1A) had observers determine whether a target $\mathrm{L}$ or $\mathrm{R}$ appeared among seven other letters. Observers fixated on a "+" until the target appeared, but prior to its appearance, an abrupt onset cue appeared at one of the eight potential target locations. After a stimulus onset asynchrony (SOA) of $50 \mathrm{msec}$, the target display appeared. The target appeared equally often at each location, but independent of the cue's location; the cue's and target's locations therefore coincided by chance. Jonides observed faster RTs for cued targets than for uncued targets; this suggests that the cue captured attention. Although not used by Jonides, it is not uncommon to use a target-never-cued procedure, in which the target appears at uncued locations only. If RTs are slower in the uncued condition than they are when no cue appears, it can be inferred that the cue captured attention.

\section{Irrelevant Singleton Paradigm}

The irrelevant singleton paradigm differs from the spatial precuing paradigm only along the cue-target synchrony dimension, because the cue always appears simultaneously with the target (Hillstrom \& Yantis, 1994; Jonides \& Yantis, 1988; J. T. Todd \& Van Gelder, 1979; S. Todd \& Kramer, 1994; Treisman \& Gelade, 1980; Yantis \& Egeth, 1999; Yantis \& Hillstrom, 1994; Yantis \& Jonides, 1984). For ex- ample, Yantis and Jonides (1984; see Figure 1B) had observers search for a prespecified target letter (E) among several nontargets $(\mathrm{H}, \mathrm{S}$, and $\mathrm{R})$ and had them indicate whether the target was present or absent. The total number of letters in the display (set size) was varied from trial to trial, and observers first saw a display containing figure-eight placeholders. The search display was revealed by erasing some placeholders from the screen while simultaneously removing segments from the remaining placeholders so as to create a letter at each of the remaining positions (nononset letters). Simultaneous with the removal of the segments and placeholders, a new, abruptly onset letter (the cue) appeared in a previously unoccupied location. This new letter (target-onset condition) was the target by chance. On other trials the target was a nononset letter (target-nononset condition), or was absent (target-absent condition).

Yantis and Jonides (1984) found that RTs in the targetonset condition did not increase as set size increased. This suggests that the abruptly onset letter captured attention, causing observers to shift their attention directly to its location first for all set sizes. Because the abruptly onset target captured attention, it was the only item searched, thereby causing RT to be unaffected by set size. In contrast, RTs in the target-absent and target-nononset conditions increased as a function of set size. This suggests that for larger set sizes it took observers longer to locate the target, or to respond that the target was absent, because they had to search more items after attention had not shifted directly to the target. Thus, attentional capture is obtained when search is more efficient in the target-onset condition than in the other conditions.

\section{Distractor Interference Paradigm}

The distractor interference paradigm developed by Theeuwes (1991a, 1991b, 1992, 1994, 2004) is similar to the irrelevant-singleton paradigm, because the cue and target appear simultaneously, but it differs from it because the cue's and target's locations never coincide. For example, Theeuwes (1992; see Figure 1C) had observers search for a green circle among green diamonds and identify the orientation of a bar inside it. The green circle was a feature singleton, an item that differed by a single feature (curvature) from the other items. In a distractor-absent condition, all of the items were green; whereas in a distractor-present condition, one diamond was red, representing a color singleton distractor. Theeuwes found that RTs were slower in the distractor-present than in the distractor-absent condition. This was presumably due to attention shifting to the distractor first, which slowed RTs after attention shifted to find the target. ${ }^{1}$ Because this occurred when the distractor was irrelevant to finding the target - it never occurred at the target's location, and differed from it in color and form - the capture seems to be stimulus-driven.

\section{The Contingent Orienting Hypotheses}

\section{Folk et al.'s (1992) Contingent Involuntary} Orienting Hypothesis

The most influential theory to propose that capture is mediated by attentional control is Folk et al.'s (1992) contingent involuntary orienting hypothesis $(\mathrm{CIOH})$. This 
A

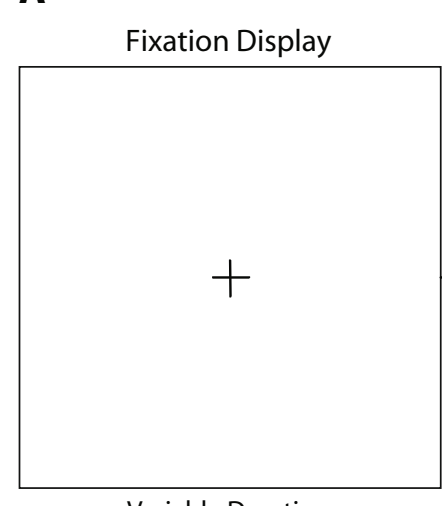

Spatial Precuing: Jonides (1981)

Variable Duration
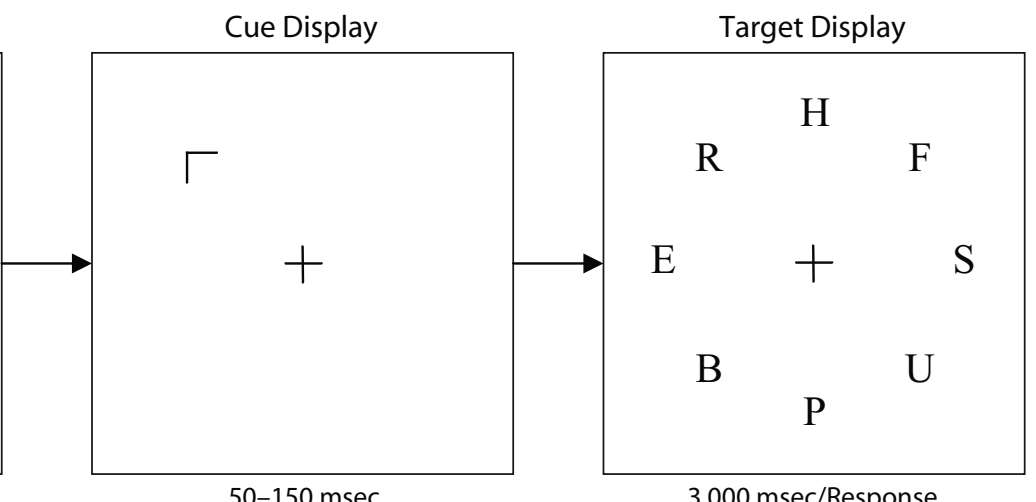

B

Irrelevant Singleton: Yantis \& Jonides (1984)
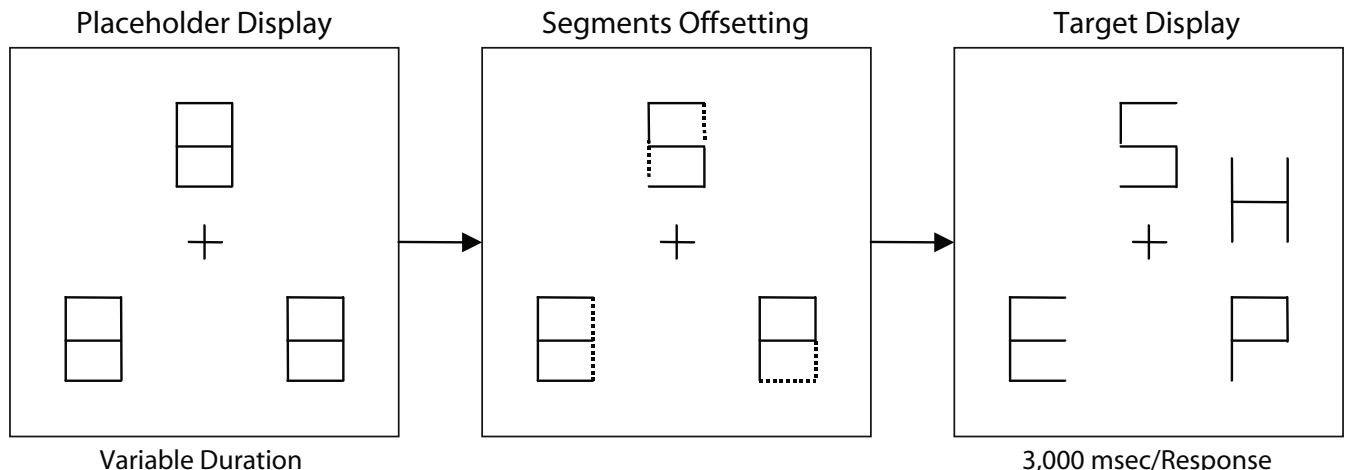

3,000 msec/Response

C

Distractor Interference: Theeuwes (1992)
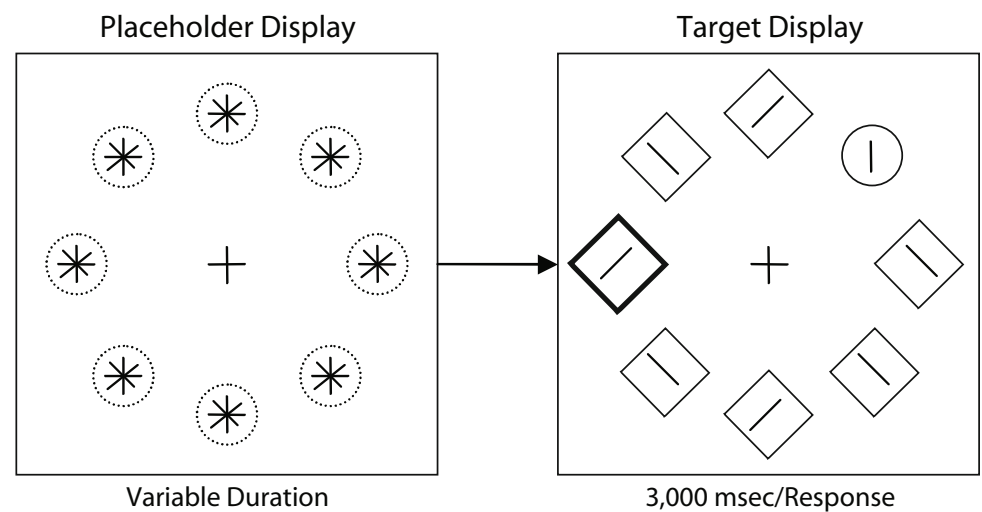

Figure 1. Sample trial sequence from each of the attentional capture paradigms.

hypothesis states that involuntary attentional capture is contingent on a salient event being featurally similar (relevant) to a feature relevant to locating a target. According to Folk et al., (1992) observers place target-relevant feature information into attentional sets, a component of working memory that includes all information necessary for locating the target (Folk, Leber \& Egeth, 2002; Folk \& Remington, 1996, 1998, 1999; Folk et al., 1993; Folk et al., 1994). This information mediates capture via top-down control over which features to attend and, potentially, which to ignore. Specifically, salient stimuli that are relevant (simi- lar) to any target-relevant feature will capture attention, but those that are irrelevant (dissimilar) will not. Thus, attentional control settings allow attention to be captured by relevant stimuli, but withheld from irrelevant stimuli.

Consider Folk et al.'s (1992) study (see Figure 2), in which observers identified a target presented at one of four locations. In their Experiment 2, the target $(\mathrm{X}$ or $=)$ was a single red item among three white items. The red item should, therefore, have comprised the attentional set, because it was relevant to locating the target. Prior to the target's appearance, sets of four dots were presented 
around each potential target location; one set was red (the cue) and the other three were white. The $\mathrm{CIOH}$ predicts attention will be captured by the red-dot cue, because "red" was relevant. Indeed, Folk et al. (1992) observed capture in this condition and compared the result with one from a condition in which the target was an onset singleton (an X or $=$, appearing alone), whereas the cue was the same as that just described. Consistent with the $\mathrm{CIOH}$, capture was not observed, presumably because the red-dot cue was dissimilar and irrelevant to the target's "onset" feature.

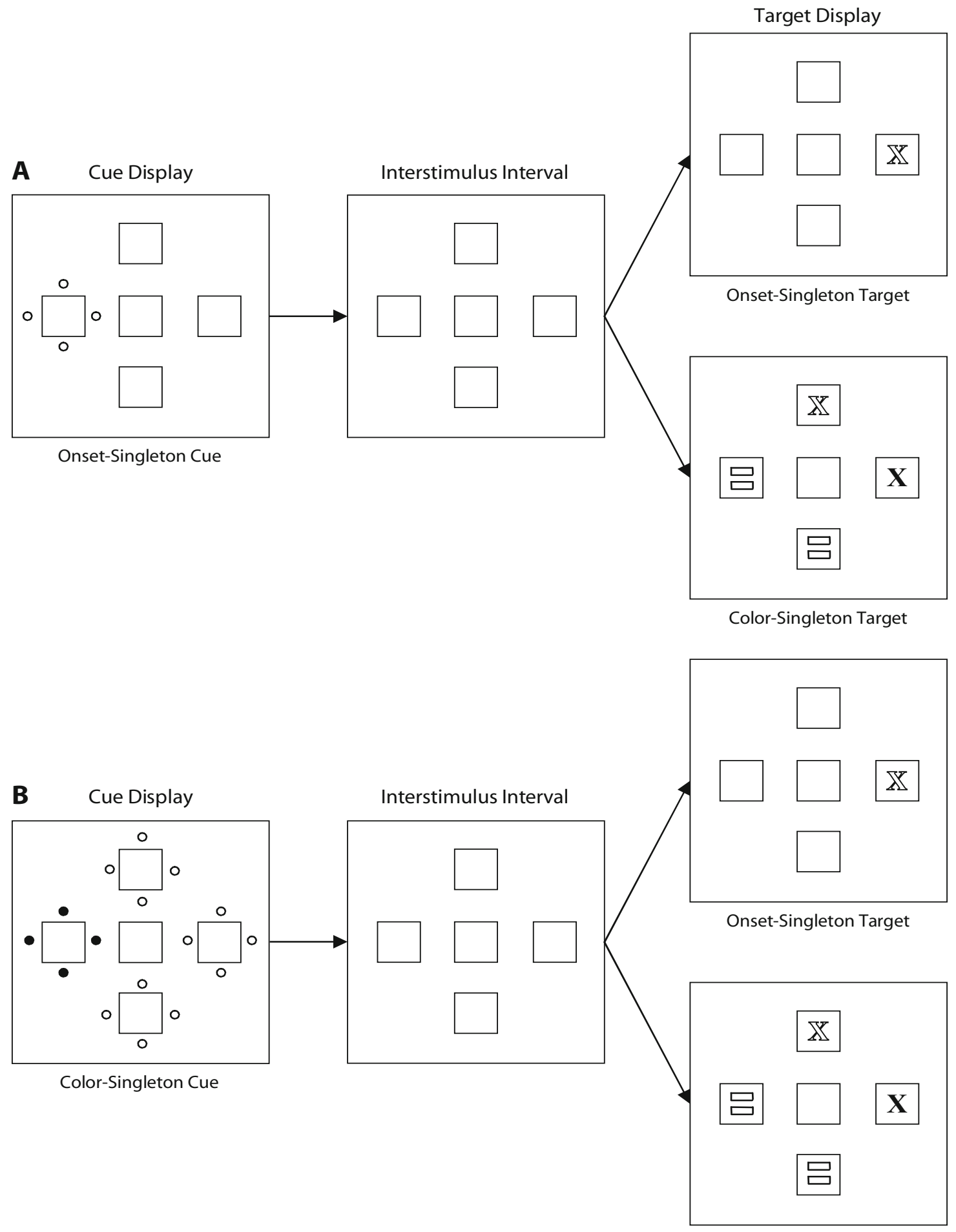

Color-Singleton Target

Figure 2. Trial sequence from Folk, Remington, and Johnston (1992). Outlined characters were white and bold stimuli were red. All stimuli were presented against a black background. 
It should be noted that attentional control settings are inclusive, not exclusive. This stems from Pratt and $\mathrm{McAu}-$ liffe's (2002) finding that a cue captures attention if at least one of its features is relevant to the target, even when another feature is irrelevant. Pratt and McAuliffe (2002) had some observers identify an onset singleton target and others a color singleton target. Prior to the target's appearance an onset singleton cue, a color singleton cue, or a combination cue (an onset singleton colored red) was presented. Consistent with the $\mathrm{CIOH}$, in the red target group the red cue captured attention but the onset cue did not; whereas in the onset target group the onset cue captured attention but the red cue did not. Presumably, the combination cue captured attention in both groups because it shared at least one feature with the target in each group ("red" in the red target group, "onset" in the onset target group). Indeed, this result was obtained even though one of the combination cue's features was irrelevant in each group; this suggests attentional control settings to be inclusive, not exclusive.

Exactly how do top-down and bottom-up mechanisms mediate capture? To begin, visual stimuli are assumed to be preattentively processed in parallel to determine what features are present in the visual field (e.g., Broadbent, 1958; Egeth, 1977; Treisman, 1969; Treisman \& Gelade, 1980; Wolfe, Cave, \& Franzel, 1989). After this preattentive feature analysis, attention is allocated to certain stimuli or regions in visual space by an attentive mechanism. Proponents of stimulus-driven capture state that attention is automatically allocated to stimuli and/or regions discrepant from their backgrounds (salient) because of evolutionary necessity to attend to salient and potentially dangerous stimuli. In contrast, proponents of contingent capture state that task demands and expectancies (control settings) reconfigure the attentive mechanism to allocate attention only to stimuli perceived to be task relevant. Thus, attention will be captured by stimuli sharing a feature (or features) with the attentional set, but will be withheld from salient but irrelevant stimuli that do not share any features with the attentional set.

Folk et al.'s (1992) hypothesis is consistent with Wolfe et al.'s (1989) Guided Search models of visual search (Wolfe, 1994, 1998, 2001; Wolfe, Butcher, Lee, \& Hyle, 2003). These models suggest that, during visual search, observers will first search in parallel to segregate items that share relevant features with a target from those items that do not. It is likely that observers in Folk et al.'s (1992) experiments segregated the relevant cue from any irrelevant stimuli in the cuing display because it matched a target-relevant feature, thus giving the cue attentional priority. Indeed, the Guided Search models and the $\mathrm{CIOH}$ postulate that target-relevant features will guide visual attention.

Consistent with the CIOH (Folk et al., 1992), Bacon and Egeth (1994) demonstrated that capture by a salient but irrelevant singleton distractor may be contingent on the target also being a singleton. Bacon and Egeth noted that when the target is a singleton, as in Theeuwes (1992; see Figure 1C), observers can opt to use a singleton search; that is, instead of searching for target-specific features (a "green circle" in Theeuwes's 1992 experiment), observers can set their attentional control settings to detect an abstract singleton feature. If singleton search is used, a singleton distractor should capture attention because it is relevant to the attentional set. ${ }^{2}$ Indeed, Bacon and Egeth found that when a target had to be located using a feature search, a singleton distractor did not capture attention, presumably because of the dissimilarity between the singleton distractor and the nonsingleton target. ${ }^{3}$

Both Folk et al.'s (1992) and Bacon and Egeth's (1994) hypotheses state that attentional capture results from feature relevance between a cue and a target-localizing feature. ${ }^{4}$ However, if the only feature that ever comprises an attentional set is that which distinguishes the target, neither hypothesis can account for capture observed in experiments using a nonlocalized target (Atchley, Kramer, \& Hillstrom, 2000; Gibson \& Kelsey, 1998; Jonides, 1981). This limits the applicability of the CIOH (and singleton search), and raises the question whether or not other features ever comprise the attentional set. If not, such instances of capture could be construed as evidence for stimulus-driven capture.

\section{Gibson and Kelsey's (1998) Displaywide Contingent Orienting Hypothesis}

Gibson and Kelsey (1998) suggested that attentional sets can be based on features not designating the target's location. Gibson and Kelsey (Figure 3) had observers identify whether a target $\mathrm{H}$ or $\mathrm{U}$ appeared among E, P, and S. All letters appeared simultaneously in red, with the same size and orientation, so the target was not distinct. The cue was a red color singleton or an onset singleton. According to the $\mathrm{CIOH}$, neither cue should capture attention, because no target-relevant feature was included in the attentional set. Contrary to this prediction, Gibson and Kelsey observed capture from both cues. Rather than attributing this to a stimulus-driven capture of attention, they attributed it to feature similarity between each cue and features signaling the target display's appearance; that is, the "onsets" of "red" letters were displaywide features that comprised observers' attentional sets as a signal for the target display's appearance, so that target search could begin. When these displaywide features were detected in the cues, the attentive system would have directed attention toward them because they were relevant.

Gibson and Kelsey's (1998) explanation was supported by their Experiment 2, in which the letters were all white, leading to attentional sets based on the displaywide features "onset" and "white." In this case, the onset cue was relevant, but the red color singleton cue was not, leading Gibson and Kelsey to predict capture by the onset singleton but not by the color singleton; this is, in fact, what they observed. The results from both experiments suggest that capture can be mediated by features other than those designating the target's location. Gibson and Kelsey's displaywide contingent orienting hypothesis $(\mathrm{DCOH})$ states that a salient stimulus will capture attention if it is relevant to a feature associated with the target display's appearance. Importantly, the hypothesis accounts for capture in cases where the target is not localized, results that the 

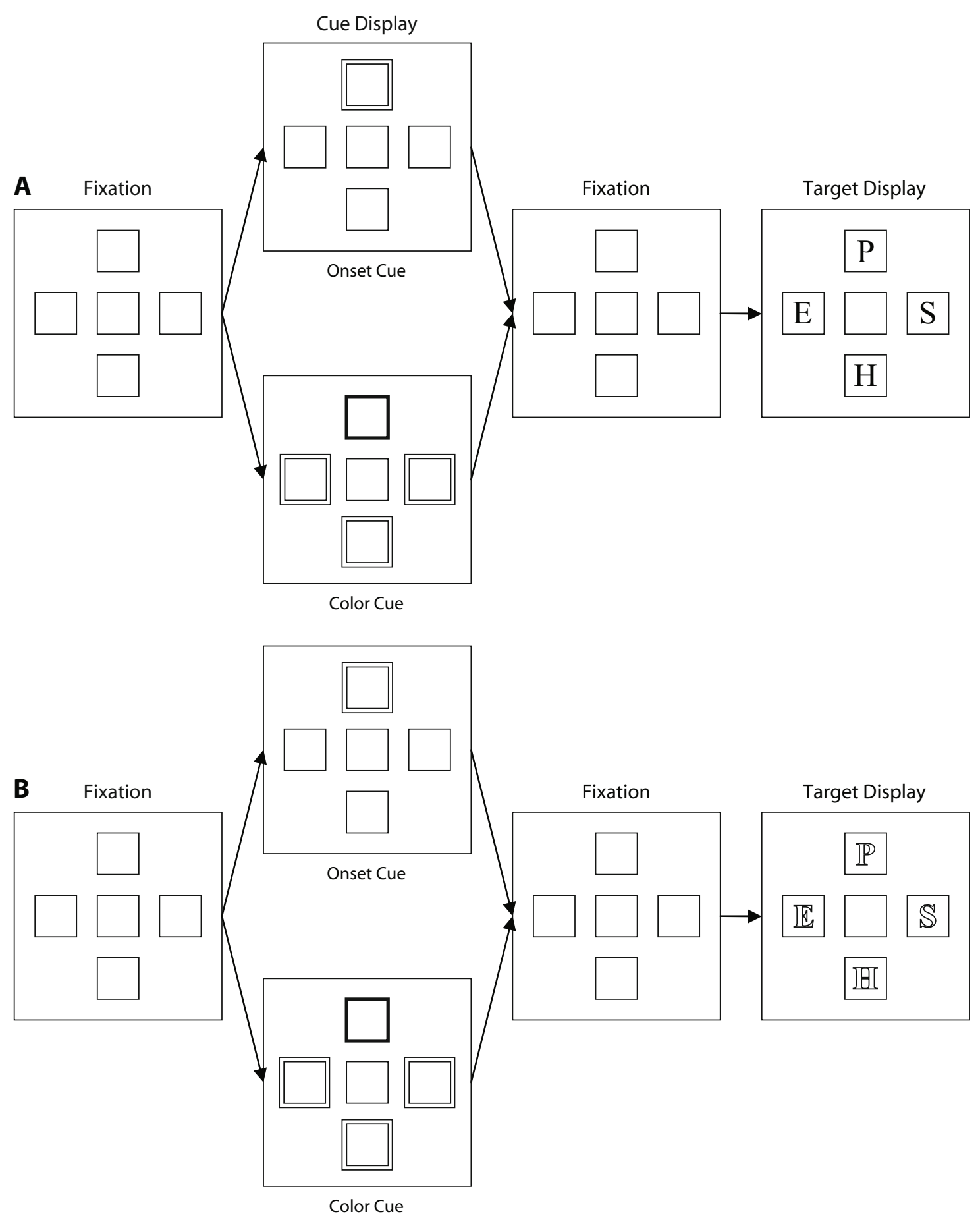

Figure 3. Trial sequence from Gibson and Kelsey (1998). Outlined stimuli were dark gray, double outlined stimuli were white, and bold stimuli were red. All stimuli were presented on a black background.

$\mathrm{CIOH}$ cannot explain. However, this does not mean that the DCOH cannot account for capture in experiments that used a localized (or singleton) target. Indeed, a targetrelevant feature not only designates a target's position within a display but also signals the appearance of target display. Thus, the DCOH can account for capture with localized or nonlocalized targets, whereas the $\mathrm{CIOH}$ only accounts for capture with localized targets as long as the capturing event contains a distinctive feature that can be used to localize the target.

However, there is an important qualification to Gibson and Kelsey's (1998) hypothesis, but one that extends its applicability. Johnson, Hutchison, and Neill (2001) observed capture from red and green color singletons when 
a target display included all red or all green letters. This was observed even when the colors of both the singleton and the letters were blocked, so observers had strong control over which color to attend and which to ignore. The fact that capture was elicited by cues not identical to the color of the target display seems to undermine Gibson and Kelsey's hypothesis, because the DCOH would seem to have predicted that Johnson et al. would observe capture only from cues with the same color as the target display letters.

The DCOH can be extended to accommodate these seemingly problematic results. As Johnson et al. (2001) suggested, there may not be an identical match between the defining feature of a singleton and a displaywide feature required for capture to be elicited; rather, a similarity between the singleton and a displaywide feature may be sufficient. A singleton might capture attention, in other words, if its defining feature and a displaywide feature lie along the same feature dimension ("color," in Johnson et al.). Thus, instead of creating attentional sets for specific displaywide features, observers might opt for more loosely defined attentional sets based on "feature changes" instantiated between the presentation of the cuing display and target display. For example, the feature change in Johnson et al.'s experiments was the "color change" in the transition from the mostly white cuing display to the all red (or green) target display. If color change comprised the attentional set, both the red and the green color singletons should have (and did) capture attention, because the color change at their locations would have been relevant to the color change associated with the target display's appearance.

Thus, there are two ways to instantiate the DCOH. First, Gibson and Kelsey's (1998) interpretation states that capture will be elicited by singletons that are identical to a displaywide feature. Second, Johnson et al.'s (2001) interpretation states that capture will be elicited by a singleton with a defining feature change that lies along the same dimension as does a feature change associated with the target display's appearance. Because Gibson and Kelsey's version is subsumed by Johnson et al.'s, this article focuses mainly on the latter interpretation. This is so because a cue identical to a displaywide feature (feature change) is necessarily similar to that feature (feature change). Hence, throughout this article $\mathrm{DCOH}$ will refer to Johnson et al.'s interpretation. However, if a capture effect can be accounted for by either interpretation, it would be considered a contingent capture effect, due to the cue's relevance to the attentional set.

Especially important in Johnson et al.'s (2001) interpretation is that the logic of the DCOH can be applied to experiments from all three paradigms, because in an experiment from any paradigm the appearance of a target display will be associated with a feature change in the transition from a pretarget (fixation or cuing) display to a target display. For example, recall how Yantis and Jonides (1984) observed capture from an onset singleton in the irrelevant-singleton paradigm. Although this result appears to be stimulus driven, it can be accounted for by the $\mathrm{DCOH}$, because the target display's appearance was asso- ciated with a "dynamic change" that could have comprised the observer's attentional set. This dynamic change was the offset of the placeholders and segments present in the fixation display but absent in the target display. Because this dynamic change was useful for signaling the target display's appearance, it could have comprised the attentional set. Because the onset singleton was a "dynamic change," it was relevant to the attentional set; hence, the DCOH predicts capture, which was observed.

Similarly, the DCOH can explain capture by irrelevant color singletons in the distractor interference paradigm. Recall that Theeuwes (1992) presented displays of green shapes that were simultaneously onset on a black background. The onset of these green stimuli produced color changes between each item and the background; "color change" was therefore useful for signaling the target display's appearance, and could have comprised the attentional set. Because the red color singleton was a color change between the green and the red stimuli, it was relevant to the attentional set; hence, the $\mathrm{DCOH}$ predicts capture, which Theeuwes (1992) obtained.

The DCOH also accounts for similar results when a premask display is present prior to the target display and the singleton distractor appears in this premask display. For example, Theeuwes et al. (2000; see also Theeuwes \& Chen, 2005) presented a premask display with nine gray diamonds, each overlaid on a gray circle and with a gray figure-eight placeholder inside. Prior to the target display, one of these diamond-circle combinations changed from gray to red and represented a singleton distractor. The target display was revealed by erasing all but one diamond (the target) simultaneously with segments from each figure eight to form letters. The target display was associated with an offset of stimuli; hence, observers could have based their attentional sets on a dynamic change to signal the target display's appearance. Because the distractor was a transient (dynamic) color change, it was relevant to the dynamic change that could have comprised observers' attentional sets; hence, the DCOH predicts capture, which Theeuwes et al. (2005) observed.

\section{CIOH Versus DCOH?}

The $\mathrm{CIOH}$ and $\mathrm{DCOH}$ are similar in that both state that capture is contingent on a cue's relevance to the attentional set, but they differ on what feature association between a cue and an attentional set must exist for the cue to capture attention. According to the $\mathrm{CIOH}$, a cue will capture attention if it is relevant to a feature designating the target's location. In contrast, according to the $\mathrm{DCOH}$, a cue will capture attention if it is relevant to a feature (feature change) associated with the target display's appearance. Unlike the $\mathrm{CIOH}$, the $\mathrm{DCOH}$ does not require the target to be localized, but it can be, because a feature designating a target's location within a display will also be associated with the target display's appearance. In such situations, both hypotheses will predict capture if the cue is relevant to that target-localizing feature. If a target is not localized, the $\mathrm{CIOH}$ always predicts no capture, because there is no target-relevant feature to comprise the attentional set. In contrast, the DCOH will predict capture if the cue is rel- 
evant to a displaywide feature (feature change) associated with the target display's appearance.

This brief comparison begins to reveal the DCOH's importance; that is, it explains capture in terms of topdown involvement in situations where the $\mathrm{CIOH}$ predicts no capture and would be unable to account for an observed capture effect. This being said, many capture effects previously considered evidence for stimulus-driven capture (because the $\mathrm{CIOH}$ and singleton search could not explain the effect) might not be stimulus-driven, because the $\mathrm{DCOH}$ can account for them. In this regard, it is noteworthy that the $\mathrm{CIOH}$ has received 301 citations (noted in the 1992-August 2005 bound Social Sciences Citation Index), including numerous empirical tests. ${ }^{5}$ In contrast, the $\mathrm{DCOH}$ has been cited just 47 times, and only two direct empirical tests of it have been published (Atchley et al., 2000; Johnson et al., 2001; see also Franconeri, Simons, \& Junge, 2004, who interpreted their results as possible support for the DCOH). Indeed, most citations of Gibson and Kelsey's (1998) study occur with Folk et al.'s (1992) study, and only as supportive evidence for the $\mathrm{CIOH}$. Hence, there has been little consideration of the $\mathrm{DCOH}$ as an alternative or an addition to the $\mathrm{CIOH}$ as an explanation of capture, even though the $\mathrm{DCOH}$ can clearly account for results that the $\mathrm{CIOH}$ cannot.

The goal of this review is to demonstrate the importance of the $\mathrm{DCOH}$ in relation to the $\mathrm{CIOH}$ as an account for attentional capture. This is done by using the logic of the DCOH to extend Folk et al.'s (1992) hypothesis to cases in which it was previously unable to explain capture. To accomplish this goal, I will consider experiments in which both hypotheses make the same prediction (for or against capture) and experiments in which the hypotheses make opposing predictions. This is done by crossing the predictions of both hypotheses, resulting in a 2 (DCOH: capture predicted vs. capture not predicted $) \times 2(\mathrm{CIOH}$ : capture predicted vs. capture not predicted) factorial. As seen in Figure 4, both hypotheses make the same prediction in two cells (I and IV) and opposing predictions in the other two cells (II and III). By discussing experiments associated with each cell, this review will demonstrate how important a consideration of the $\mathrm{DCOH}$ is. In addition (and perhaps more important), the review will also reveal that there is no conclusive evidence for purely stimulus-driven capture.

\section{Outline of the Empirical Review}

This review follows the factorial design of Figure 4 by discussing Cells I-IV in turn. The discussion of each cell includes experiments from each attentional capture paradigm to show how the $\mathrm{DCOH}$ and/or $\mathrm{CIOH}$ can (or cannot) explain capture obtained (or not) in experiments from each paradigm. Because it would be cumbersome to include detailed discussions of each of the more than 301 studies in the literature, and because many experiments within and across labs are similar with respect to procedures, stimuli, and results, to avoid redundancy I discuss one or two prototypical experiments from each paradigm per cell. To supplement these discussions, I include one table for each cell (Tables A1-A4, except for Cell III,

\begin{tabular}{|c|c|c|}
\hline & & $\mathbf{O H}$ \\
\hline & Capture Predicted & Capture Not Predicted \\
\hline Capture & $\begin{array}{l}\text { I. The } \mathrm{DCOH} \text { and the } \mathrm{CIOH} \text { both } \\
\text { predict attentional capture, because } \\
\text { a feature similarity exists between } \\
\text { the cue and the target-localizing } \\
\text { feature. This target-localizing } \\
\text { feature is also associated with the }\end{array}$ & $\begin{array}{l}\text { IIa. Target is not localized and the } \\
\text { cue is related to a displaywide } \\
\text { feature associated with the target } \\
\text { display's appearance. The DCOH } \\
\text { can explain all capture effects, but } \\
\text { the CIOH cannot explain any. }\end{array}$ \\
\hline Predicted & $\begin{array}{l}\text { target display's appearance. This is } \\
\text { the 'least informative' cell, because } \\
\text { the DCOH does not explain any } \\
\text { result not already explained by the } \\
\text { CIOH. }\end{array}$ & $\begin{array}{l}\text { IIb. Target is localized. In some } \\
\text { cases, countervailing information in } \\
\text { the attentional set prevents capture. } \\
\text { In other cases, the cue is related to a } \\
\text { displaywide feature associated with } \\
\text { the target display's appearance. }\end{array}$ \\
\hline $\begin{array}{l}\text { Capture Not } \\
\text { Predicted }\end{array}$ & $\begin{array}{l}\text { III. If a study had obtained } \\
\text { attentional capture, it would indicate } \\
\text { that the DCOH is unable to account } \\
\text { for all attentional capture effects. } \\
\text { However, a capture effect would be } \\
\text { consistent with the CIOH. This } \\
\text { would indicate that the CIOH can } \\
\text { explain capture effects that the } \\
\text { DCOH cannot explain. However, } \\
\text { there is no known study that fits into } \\
\text { this cell. }\end{array}$ & $\begin{array}{l}\text { IV. Studies in this cell that did not } \\
\text { obtain capture are consistent with } \\
\text { the DCOH and CIOH. That is, there } \\
\text { was no feature association between } \\
\text { the cue and attentional set. In } \\
\text { contrast, any study that observed a } \\
\text { capture effect potentially observed a } \\
\text { stimulus-driven capture of attention. } \\
\text { However, for all experiments that } \\
\text { reported a capture effect, the result } \\
\text { could have been due to observers } \\
\text { using a 'singleton search.' }\end{array}$ \\
\hline
\end{tabular}

Figure 4. The $2 \times 2$ factorial delineating whether the DCOH and $\mathrm{CIOH}$ make the same or different predictions for attentional capture. 
discussed later; see the Appendix), which summarizes experiments from the literature that fall into that cell. In each table, experiments are ordered by paradigm and by whether capture was obtained. Each experiment is listed with the features associated with the cue, the target (if featurally distinct), and target display (displaywide features). By comparing the cue with the displaywide features and the target-relevant features, it can be determined whether the $\mathrm{DCOH}$ and/or the $\mathrm{CIOH}$ (or neither) predicts capture. That is, the tables can be used to see whether a cue is relevant to (1) the target-localizing feature, (2) a displaywide feature, (3) both, or (4) neither.

In summary, this review discusses how the results of experiments from the attentional capture literature can be explained by the $\mathrm{CIOH}$ and/or $\mathrm{DCOH}$, or by neither. This review will demonstrate how and why the $\mathrm{DCOH}$ is important and why it should not be overlooked. This review will also demonstrate how the $\mathrm{DCOH}$ can account for most instances of capture, but not all. Finally, this review reveals that by including the abstract target-relevant property "singleton" in the attentional set, all capture effects in the literature can be explained via top-down involvement.

\section{Exclusion of Experiments With an Endogenous Cuing Component}

Because this review is related to the top-down versus bottom-up debate, I do not include capture effects involving endogenous cuing - that is, capture that may have come about because observers strategically used a cue to locate a target. Examples include those in which the cue's location coincided with the target's location at greaterthan-chance levels (e.g., Bravo \& Nakayama, 1992; Chastain \& Cheal, 1998; Folk \& Annett, 1994; Hillstrom \& Yantis, 1994; Horstmann, 2002; Richard, Wright, \& Ward, 2003). Such experiments are excluded even if their results can be explained by the $\mathrm{CIOH}$ and/or the $\mathrm{DCOH}$, because the potential for strategic use of the cue allows for the observed capture effects being voluntary rather than involuntary.

\section{Exclusion of Experiments With Cues That Were Likely Not Salient}

Other experiments not included are those in which capture was not observed because the perception of the cue as a salient singleton could potentially have been prevented, which would have made the cue physically unable to capture attention. For example, using the irrelevant-singleton paradigm, Yantis and Jonides (1990) failed to find capture from an onset singleton because, on every trial, a central arrow guided observers' attention to the target's location prior to the onset singleton's appearance. The absence of capture was likely due to observers focusing their attention on the target's location prior to the cue's appearance; accordingly, it was not perceived. Similarly, Theeuwes (2004) and Theeuwes and Burger (1998; Experiment 2) found that inefficient serial search prevented capture by a color singleton. This was presumably due to spatial attention being too narrowly focused to simultaneously perceive the singleton with other items that concealed its status as a salient singleton. In other studies, a cue did not capture attention, presumably because it was not salient enough to do so. For example, Atchley et al. (2000) presented a luminance-transient cue that did not capture attention. However, the ratio of luminance change was too small to elicit capture, because when larger luminance changes were used, the cue captured attention (Rauschenberger, 2003b). Finally, studies such as Martin-Emerson and Kramer's (1997) failed to yield capture because strong perceptual changes in the target display overpowered and masked the cue. Specifically, Martin-Emerson and Kramer found that when the number of offsetting stimuli in a target display was equal to or greater than the number of stimuli onset at an onset singleton's location, the onset singleton did not capture attention. Hence, the physical change across the display was as strong as or stronger than the physical change associated with the cue, which overpowered the salience of the cue.

\section{Cell I: Both the DCOH and CIOH Predict Attentional Capture}

Recall that the $\mathrm{DCOH}$ and $\mathrm{CIOH}$ make the same prediction in two cells in Figure 4. For experiments associated with Cell I (Table A1), both hypotheses predict capture to be observed. In Table A1, most experiments used precuing procedures and stimuli similar to Folk et al.'s (1992), and the cue was featurally relevant to the target-localizing feature that was also useful for signaling the target display's appearance. Both the $\mathrm{CIOH}$ and the $\mathrm{DCOH}$, therefore, predict capture. However, because the $\mathrm{CIOH}$ can account for these results, Cell I (and the experiments in Table A1) is the least informative for demonstrating the DCOH's importance. This is so because, although the $\mathrm{DCOH}$ can explain these results, the $\mathrm{CIOH}$ can just as easily account for them. Hence, by considering Cell I alone, the difference between the hypotheses cannot be discerned. Indeed, this is true for all of the experiments by Folk and his colleagues (Folk \& Remington, 1996, 1998, 1999; Folk et al., 1992; Folk et al., 1994).

For example, Rauschenberger (2003b, Experiment 1) presented target displays containing nontarget letters revealed by removing segments from figure-eight placeholders. The nontarget letters were revealed simultaneously with the onset of a target letter. Because the target was an onset singleton, the $\mathrm{CIOH}$ predicts capture from the onset singleton cue that preceded the target display. Also, because the target display's appearance was associated with "offset" and "onset" features (dynamic change), the DCOH also predicts capture from the onset singleton, because the onset singleton (a dynamic change) was relevant to features that signaled the target display's appearance. Hence, both the $\mathrm{DCOH}$ and $\mathrm{CIOH}$ can explain Rauschenberger's (2003b) results.

The same conclusion can also be drawn about the capture by a color singleton observed by Remington, Folk, and McLean (2001, Experiment 1). Target displays contained one red target among three white nontargets (the same target display as that used by Folk et al., 1992); hence, "red" was useful in detecting the appearance of the target display and for designating the target's location. The cue was a red color singleton that was featurally relevant 
to an attentional set for "red"; thus, the DCOH and the $\mathrm{CIOH}$ both predict attentional capture, as Remington et al. (2001) found. However, as with Rauschenberger's (2003b) results, because both hypotheses account for this result the DCOH cannot be said to explain anything not already accounted for by the $\mathrm{CIOH}$.

The results of Theeuwes (1991a, Experiment 1) illustrate how both the $\mathrm{DCOH}$ and the $\mathrm{CIOH}$ can explain capture obtained in distractor interference experiments. For one group, the target display contained one red or green circle designating the target's location, which appeared among several green or red circles, respectively. For a second group, the target display contained all red circles with one (the target's location) being brighter or dimmer than the others. In the first group, "color" or "color change" was associated with the target's location and with the target display's appearance, because the onset of the colored stimuli elicited a color change between the stimuli and the black background. In contrast, for the second group, "luminance" or "luminance change" was relevant. For both groups, these features (or feature changes) could have comprised the observers' attentional set, because they were useful for signaling the target display's appearance and locating the target. Hence, for the first group, the attention-capturing color singleton distractor was relevant to the attentional set, whereas the attention-capturing luminance singleton distractor was relevant in the second group. Thus, for both groups, the $\mathrm{DCOH}$ and the $\mathrm{CIOH}$ account for the capture effects that Theeuwes (1991a) observed.

The experiments just described, and the others in Table A1 in the Appendix, demonstrate how, for some experiments, both the $\mathrm{DCOH}$ and $\mathrm{CIOH}$ account for capture in the same experiment. Taken at face value, these results do not say anything about the DCOH's importance, because the $\mathrm{CIOH}$ (the original contingent capture hypothesis) can just as easily account for the results; hence, the DCOH does not add anything beyond what is already accounted for by the $\mathrm{CIOH}$. Thus, to demonstrate its importance, in the next section I discuss results that can be accounted for by the $\mathrm{DCOH}$, but not the $\mathrm{CIOH}$, because the target is not localized, but is relevant to a displaywide feature.

\section{Cell IIa: The DCOH Predicts Capture, but the CIOH Does Not (Nonlocalized Target)}

For experiments discussed in this section (Table A2), the $\mathrm{DCOH}$ predicts capture, but the $\mathrm{CIOH}$ predicts no capture. This is so because target displays in all of the experiments in this section included a target indistinguishable from nontargets on the basis of any feature except identity. The $\mathrm{CIOH}$ predicts no capture in these experiments, because no feature relevant to target localization was available to comprise the attentional set. However, because observers must rely on some perceptible feature to determine when the target display appears and begin target search, some displaywide feature must comprise the attentional set; according to the $\mathrm{DCOH}$, a cue relevant to a displaywide feature will capture attention. Thus, whenever a capture effect is observed for the experiments reviewed in this section, the results establish the importance of the $\mathrm{DCOH}$ in relation to the $\mathrm{CIOH}$, because the $\mathrm{DCOH}$ accounts for these capture effects in terms of top-down involvement, whereas the $\mathrm{CIOH}$ cannot explain them.

Several experiments in Table A2 were discussed earlier (Gibson \& Kelsey, 1998; Johnson et al., 2001; Jonides, 1981; Yantis \& Jonides, 1984). In the studies conducted by Gibson and Kelsey and by Jonides, the $\mathrm{CIOH}$ predicts no capture because the target had no distinguishing features. However, in Gibson and Kelsey's experiment, as in Jonides's, the onset singleton cue was featurally relevant to the "onset" associated with the appearance of the target display stimuli. Similarly, in Johnson et al.'s study, the red or green color singleton cue was featurally relevant to the color change useful for signaling the appearance of the target display. Hence, in these three experiments, the DCOH can account for the observed capture effects, because the cues were relevant to a feature associated with the target display's appearance, whereas the $\mathrm{CIOH}$ cannot explain these results, because the target was not distinct.

As another example, consider Atchley et al.'s (2000) Experiment 3, which is one of the few studies that directly tested the DCOH. Target displays were associated with a dynamic change, because the appearance of the target display was signaled by the onset of letters and offset of segments from figure-eight placeholders, which created letters. The target was an abrupt onset or offset letter indistinguishable from the nontargets. Because the target was not localized, the $\mathrm{CIOH}$ predicts no capture, and observers could only place the displaywide features "onset" and "offset" (or simply "dynamic change") into their attentional sets. The cue was an onset or offset singleton (a dynamic change), both of which were relevant to the displaywide features useful for signaling the target display's appearance. Thus, the DCOH predicts capture from both the onset cue and the offset cue, which is the result that Atchley et al. observed. As was the case with the experiments listed in the preceding paragraph, Atchley et al.'s results demonstrate the importance of the $\mathrm{DCOH}$, because it accounts for capture effects that the $\mathrm{CIOH}$ predicted would not occur.

Capture in the irrelevant-singleton paradigm can also be explained by the DCOH if we recall that Yantis and Jonides (1984) presented target displays containing letters - revealed by removing segments from figureeight placeholders - and one abrupt onset letter (see also Enns, Austen, Di Lollo, Rauschenberger, \& Yantis, 2001; Hillstrom \& Yantis, 1994; Miller, 1989; Yantis \& Jonides, 1990). The target was indistinguishable from the nontargets by any unique feature; hence, the $\mathrm{CIOH}$ predicts no capture from the onset singleton letter. However, because the appearance of the target display was associated with "offset" and "onset" features (or simply "dynamic change"), the onset singleton was relevant to displaywide features comprising the attentional set. Thus, the $\mathrm{DCOH}$, unlike the $\mathrm{CIOH}$, predicts (and accounts for) the capture that Yantis and Jonides (1984) observed.

Franconeri and Simons (2003, Experiments 1-3) presented target displays with several letters revealed by removing segments from placeholders; hence, the appearance of the target display was associated with a dynamic change. The difference among their three experiments was the cue used in each: An onset singleton was used in Ex- 
periment 1, a motion singleton in Experiments $2 \mathrm{~A}-2 \mathrm{C}$, a singleton "jittering" item in Experiment 2D, and an item that increased in size in Experiment 3. Each cue is defined by a dynamic change and was relevant to the dynamic change comprising the attentional set to signal the target display's appearance. Hence, the DCOH predicts (and accounts for) the capture observed in each of Franconeri and Simons's experiments, whereas once again the $\mathrm{CIOH}$ incorrectly predicts no capture in any experiment.

Also relevant is Abrams and Christ's (2003) finding that motion onset captures attention but other types of motion (motion offset, continuous motion) do not. In Experiment 1, observers saw a preview display with two rotating and two stationary placeholders. When segments were removed from the placeholders to reveal letters, one rotating item stopped (motion-offset item) while the other continued (continuous-motion item); for the stationary items, one began moving (motion-onset item) while the other remained stationary (static item). Observers were faster to identify targets presented as the motion-onset item than any other item. This was also true in their Experiment 2, in which a motion-onset singleton appeared among all static items. In both experiments, the offset of segments (dynamic change) was useful in signaling the target display's appearance and therefore could have comprised the attentional set. Because the motion-onset item was a dynamic change, the DCOH predicts capture in Experiment 2 , but the $\mathrm{CIOH}$ predicts no capture, because the target was not localized. However, because motion-offset and continuous-motion items in Experiment 1 were (in some sense) dynamic, the DCOH might not account for the capture by the motion-onset item in Experiment 1. As Abrams and Christ (2003, p. 431) stated, "an attentional set for movement in general, for changes in movement, or for the offset of the camouflaging placeholder segments would not have favored the motion-onset item over the motion-offset or continuous-motion items."

Although Abrams and Christ (2003) suggested that the capture by motion onset obtained in their Experiment 1 may have been stimulus driven, there is an alternative explanation that allows the $\mathrm{DCOH}$ to account for this result. Because the motion-onset item was likely the most salient item in the display, observers could have formed their attentional sets for "motion onset" as a means to signal the target display's appearance. This is so because the continuous-motion item probably lost its status as a dynamic (salient) item by the time the target display appeared, and the motion-offset item was potentially more difficult to detect than the motion-onset item was. If observers used motion onset to signal the target display's appearance, according to the $\mathrm{DCOH}$, the motion onset item should capture attention. ${ }^{6}$ The idea that observers formed attentional sets for motion onset (presence of motion) rather than motion offset (absence of motion) is congruent with Treisman and Souther's (1985) finding that the presence of a basic perceptible feature (the line segment on a $\mathrm{Q}$ among Os) is easier to detect than its absence (an O among Qs). (See also Neisser, 1963.)

The results of Turatto and Galfano's (2000) Experiment 1 can also be explained by the $\mathrm{DCOH}$ but not by the
$\mathrm{CIOH}$. Target displays contained one red singleton disc (cue) and five green discs, with each disc having a line inside. The target (when present) was a vertical line, and nontarget lines were randomly oriented. The cue and target locations coincided by chance, but because the target's location was indistinguishable from nontarget locations, the $\mathrm{CIOH}$ predicts no capture. However, the appearance of colored discs on the black background produced a color change that was associated with (and useful for detecting) the target display's appearance. Thus, the color change at the cue's location was relevant to that displaywide color change, leading the DCOH to predict the capture that Turatto and Galfano (2000) observed.

Conceptually similar results were reported in a distractor interference experiment by Peterson and Kramer (2001) with dynamic cues. Target displays contained featurally similar letters that were revealed by removing segments from placeholders. The letters were featurally similar, leading the $\mathrm{CIOH}$ to predict no capture. However, because the appearance of the target display was associated with the "offset" of placeholder segments (dynamic change), the onset singleton distractor (a dynamic change) was relevant to the dynamic change that signaled the target display's appearance. Thus, the $\mathrm{DCOH}$ predicts (and can account for) the attentional capture effect observed by Peterson and Kramer.

The same conclusion can be drawn regarding distractor interference experiments that used a color singleton distractor (Theeuwes \& Burger, 1998). Their target displays included colored featurally similar letters (red or green) that were onset on a black background, which instantiated a color change associated with the target display's appearance. Because the target's location was not distinct, the $\mathrm{CIOH}$ predicted no capture. However, because a color singleton distractor present in the display was defined by a color change, it was relevant to the displaywide color change associated with the target display's appearance. Thus, the $\mathrm{DCOH}$ can account for the attentional capture effects obtained by Theeuwes and Burger, whereas the CIOH cannot.

The results reviewed in this section demonstrate the importance of the DCOH, because they cannot be explained by the $\mathrm{CIOH}$, there being no distinctive feature that designated the target to be placed in the attentional set. However, the DCOH predicted capture because the cues were featurally relevant to a displaywide feature associated with (and useful for signaling) the appearance of the target display. Because the DCOH can account for these results, they can be considered "contingent" attentional capture effects. In the next section, I discuss the results of experiments that cannot be explained by the $\mathrm{CIOH}$ but can be accounted for by the $\mathrm{DCOH}$, even though the target locations in these experiments were designated by a distinctive feature.

\section{Cell IIb: The DCOH Predicts Capture, but the CIOH Does Not (Localized Target)}

\section{Experiments Reporting Attentional Capture}

In this section, the $\mathrm{CIOH}$ predicts no capture, because the cues used in the experiments discussed here were ir- 
relevant to all target-localizing features. However, just because the cue is irrelevant to all target-localizing features does not mean it is irrelevant to features associated with the target display's appearance. That is, the cue could be relevant to some feature useful for signaling the target display's appearance even though it is not relevant to localizing the target. In such cases, the DCOH predicts that the cue will capture attention, but the $\mathrm{CIOH}$ does not.

As one example, Lamy and Egeth (2003, Experiment 3) presented one group of observers with target displays containing one red, one green, one blue, one purple, and two gray circles, with one of the nongray circles designating the target's location. A second group saw displays containing one red, green, blue, or purple singleton circle among five gray circles, with the color singleton designating the target's position. For both groups, all circles were gray prior to the target display's appearance, which was associated with (1) a color change from the gray to the colored circles, and (2) the onset of the target and nontarget stimuli inside the circles. Hence, "color change" and "onset" comprised the attentional set as a means to signal the target display's appearance. The cue was an onset singleton that was irrelevant to the target-localizing feature (color) in both groups; therefore, the $\mathrm{CIOH}$ predicts no capture. However, the onset singleton was relevant to the displaywide "onset" of the target and nontarget stimuli, so the DCOH predicts capture, as Lamy and Egeth found. In fact, Lamy and Egeth noted that the DCOH was a potential explanation for their results.

Similarly, Folk et al. (1994, Experiment 4) observed capture from an onset singleton when observers could have used the "onset" of target and nontarget stimuli (a dynamic change) to signal the target display's appearance. The target was a motion singleton-that is, an item that began moving as soon as it and all of the nontarget (unmoving) items were simultaneously presented. Because the onset singleton cue was dissimilar and irrelevant to the motion singleton, the $\mathrm{CIOH}$ predicts no capture. However, because observers could use "onset" to signal the target display's appearance, the onset singleton cue was relevant to that displaywide feature. The obtained capture effect can therefore be accounted for by the $\mathrm{DCOH}$.

Riggio, Bello, and Umiltà (1998; see also Pratt \& McAuliffe, 2001; Samuel \& Weiner, 2001) observed capture by an offset singleton when observers were set to detect an onset singleton target, a result inconsistent with the $\mathrm{CIOH}$ but not with the DCOH. Observers saw a display with two placeholder boxes and responded to the presence of a target " + " in one. Prior to the target's appearance, an onset singleton cue was presented at one placeholder, an offset singleton cue was removed from a placeholder, or no cue was presented. The $\mathrm{CIOH}$ predicts no capture in the offset-cue condition because the offset singleton cue is dissimilar and irrelevant to the onset singleton target. In contrast, because the offset singleton cue and onset singleton target were both "dynamic changes," the DCOH predicts capture, as Riggio et al. found. However, because the cue and target were both dynamic singletons, singleton search also accounts for Riggio et al.'s results (Bacon \& Egeth, 1994). This alternative explanation does not diminish the fact that the $\mathrm{DCOH}$ can account for this result; indeed, both accounts explain the capture in terms of top-down involvement. Because I know of no study testing the potentially competing predictions between the $\mathrm{DCOH}$ and singleton search, these explanations cannot be disentangled.

The DCOH can also account for capture in distractor interference experiments, whereas that the $\mathrm{CIOH}$ cannot. Recall that Theeuwes (1992) found that a red diamond (color) singleton captured attention when observers were set to locate a green circle among green diamonds. Because the color singleton was dissimilar, and was irrelevant to the target, the $\mathrm{CIOH}$ predicts no capture. However, because the simultaneous onset of the colored shapes produced a color change on the black background, the "color change" that designated the color singleton was relevant to the "color change" associated with the target display's appearance; therefore, the DCOH predicts (and accounts for) the attentional capture effect that Theeuwes (1992) observed.

Similarly, Theeuwes (1994; see also Irwin, Colcombe, Kramer, \& Hahn, 2000; Wu \& Remington, 2003) had observers perform a line-orientation discrimination task after locating a red circle among green circles. The singleton distractor in this experiment was the onset of a new green circle. Because the onset singleton distractor was featurally dissimilar and irrelevant to the red circle that designated the target's location, the $\mathrm{CIOH}$ predicts no capture. However, Theeuwes (1994) preceded the target display with a placeholder display containing green circles, with several randomly oriented line segments inside each. The target display's appearance was associated with a change in color of one circle from green to red, the offset of all but one line segment inside each circle, and the onset of the new green circle. The offset of stimuli instantiated a "dynamic change" that was associated with the target display's appearance; hence, the onset singleton (a dynamic change) was relevant to the target display's appearance. Thus, the DCOH predicts (and can account for) the capture that Theeuwes (1994) observed. This result (along with those discussed here and other results summarized in Table A3) therefore shows that, even when the target is distinct among nontargets (a condition required for the $\mathrm{CIOH}$ to predict capture), the $\mathrm{DCOH}$ accounts for capture effects that the $\mathrm{CIOH}$ predicts should not occur.

\section{Experiments Reporting an Absence of Attentional Capture}

It is noteworthy that 21 , or $30 \%$, of the 70 experiments listed in Table A3 did not observe capture, even though the DCOH predicted that capture should have been obtained. These results are consistent with the $\mathrm{CIOH}$, which predicts no capture from the irrelevant cue, but are inconsistent with the DCOH's predictions. By accepting these null effects at face value, which is risky, it seems that the targetlocalizing feature in these experiments had a stronger influence on the attentional control settings than did other displaywide features. This poses the interesting question of when target localizing, rather than other displaywide features, dominates attentional control settings. However, 
because the procedures and stimuli used in some of the experiments that did obtain capture were very similar to those experiments in which capture was not found, there seem to be inconsistent results across experiments. Thus, the issue becomes what procedural characteristic (e.g., blocking cued and uncued trials; blocking or randomizing the target-localizing or cue-defining feature) caused the cue to capture attention in some experiments but not in others.

To address this issue, I examined the similarities and differences in the procedures and stimuli between experiments yielding capture and those not yielding capture. Unfortunately, no common difference could be found. This is troubling, given that these experiments used similar procedures and stimuli, leading one to expect consistent results. Thus, there is no good explanation why capture was obtained in some experiments but not in others. Although the absence of a capture effect in these experiments is inconsistent with the $\mathrm{DCOH}$, because null effects are less persuasive than significant ones I believe that the weight of the evidence in Cell II strongly favors the conclusion that the $\mathrm{DCOH}$ can account for capture effects that $\mathrm{CIOH}$ cannot explain. Nonetheless, because the glass is only $70 \%$ full in favor of the DCOH, proponents of the $\mathrm{CIOH}$ will view it as $30 \%$ full in their favor. The most conservative conclusion is that both hypotheses are needed to account for the full range of results in the attentional capture literature. However, this conclusion is weakened by two facts. First, even if only the DCOH was correct, one would not expect its predictions to be confirmed $100 \%$ of the time. Second, there is no discernible difference between the $70 \%$ of the experiments confirming the DCOH's predictions and the $30 \%$ that yield the null effect predicted by the $\mathrm{CIOH}$. It therefore becomes important to determine whether the $\mathrm{CIOH}$ correctly predicts that capture will occur under conditions for which the DCOH predicts null effects. The next section reviews results relevant to this issue.

\section{Cell III: The CIOH Predicts Capture, but the DCOH Does Not}

Because Tables A2 and A3 include more experiments than Table A1, at this point the $\mathrm{DCOH}$ can be said to account for more capture effects in the literature than the $\mathrm{CIOH}$. Thus, it is also important to consider capture that can be explained by the $\mathrm{CIOH}$ but not by the $\mathrm{DCOH}$. If such cases can be found in the literature, they would show that the $\mathrm{DCOH}$ cannot account for all capture effects in the literature and that the $\mathrm{CIOH}$ is needed. However, I was unable to locate a single case of capture that can be explained by the $\mathrm{CIOH}$ but not by the $\mathrm{DCOH}$. This suggests two things: (1) The DCOH can account for every capture effect that the $\mathrm{CIOH}$ can explain (Table A1) and cannot explain (Tables A2 and A3), and (2) the CIOH cannot explain any capture effect not already accounted for by the $\mathrm{DCOH}$. This second point is interesting, because the $\mathrm{DCOH}$ has been largely overlooked. Because the $\mathrm{CIOH}$ does not uniquely account for any capture effect, one can ask whether the hypothesis is necessary when addressing attentional capture; that is, when designing an experiment or addressing results of prior experiments, should a researcher consider the $\mathrm{DCOH}$ only, or the $\mathrm{CIOH}$ also? Although I will address this in detail in the General Summary, note that in the previous section we showed that, in $30 \%$ of the cases in which the DCOH predicted capture but the $\mathrm{CIOH}$ did not, the null effect predicted by the $\mathrm{CIOH}$ was obtained. If we assume these null results to have been produced by subtle procedural differences that I could not discern, these data suggest that the CIOH is necessary to account for the full range of results reported in the literature.

\section{Cell IV: Neither the DCOH nor the CIOH Predicts Capture}

In the final cell of Figure 4, neither the $\mathrm{CIOH}$ nor $\mathrm{DCOH}$ predicts capture. For the experiments discussed in this section, the $\mathrm{CIOH}$ predicts capture not to be found (1) because the target is not distinct and there is no targetrelevant feature to comprise the attentional set; or (2) because the target is designated by a distinctive feature to which the cue is irrelevant (Chastain \& Cheal, 1998; Gibson \& Amelio, 2000; Lamy \& Egeth, 2003). The DCOH predicts no capture because the cues used in these experiments are irrelevant to (1) all displaywide features that do not localize the target (Gibson \& Kelsey, 1998), or (2) a target-localizing feature also associated with the target display's appearance (Rauschenberger, 2003b; Theeuwes, 1992). However, only 12 of the 20 experiments in Table A4 conform to these predicted null effects; they are discussed in the next section. In contrast, eight experiments yielded capture, a finding that runs contrary to the predictions of both hypotheses.

These capture effects are potentially important because they could be construed as evidence for stimulus-driven capture. Indeed, based on the logic of the DCOH and of the $\mathrm{CIOH}$ alone, the attention-capturing stimulus in each of these eight experiments was totally irrelevant to observers' attentional sets, leading to the conclusion that these results were stimulus driven. Although such a conclusion is valid based on the assumptions of the $\mathrm{DCOH}$ and $\mathrm{CIOH}$ alone, it would be premature to draw such a conclusion without first ensuring that some other top-down theory could not account for these results. Admittedly, such a theory would be peripheral to this review, which is focused on the $\mathrm{DCOH}$ and the $\mathrm{CIOH}$. However, concluding that these eight experiments yielded stimulus-driven capture would be inappropriate if some other top-down theory accounted for the results. As we shall see, the capture effects listed in Table A4 can be explained by top-down involvement and therefore cannot be considered as evidence for stimulus-driven capture. Specifically, observers could have used a singleton search in these eight experiments, which would have made the attention-capturing singleton relevant to their attentional sets (Bacon \& Egeth, 1994; Leber \& Egeth, 2006). I discuss the implications of this for stimulus-driven capture after the following section.

\section{Results Consistent With the DCOH and the CIOH: Null Capture Effects}

Gibson and Kelsey's (1998) Experiment 2 is an example of an experiment with a nondistinct target and a 
cue irrelevant to all displaywide features. Target displays contained all white letters with a target indistinguishable from nontargets on the basis of any unique feature except identity. A red color singleton preceded the target display on half of the trials and an onset singleton on the other half (only the color singleton is relevant here). Because the target was not localized, the $\mathrm{CIOH}$ predicts no capture; and because the red color singleton was irrelevant to the displaywide features "white" and "onset," the DCOH also predicts no capture. Hence, the absence of attentional capture is consistent with both hypotheses.

Lamy and Egeth's (2003) Experiment 5 (see also Experiment 6) provides an example of a study with a distinctive target, in which neither the $\mathrm{DCOH}$ nor $\mathrm{CIOH}$ predicts capture. Fixation displays contained six sets of dark gray shapes consisting of a triangle, a circle, a square, and a diamond, with each shape overlaid on the other three, and each set designating a potential target location. The appearance of the target display was associated with the offset of all of the overlaid shapes - but one at each location - and with the onset of target and nontarget stimuli at the six locations. The target's location was designated by a specific shape (a diamond among three circles and one each of the other two shapes). The cue was a color singleton (a set of red shapes amidst sets of light gray shapes) that was irrelevant to the target-localizing shape, leading the $\mathrm{CIOH}$ to predict no capture. In addition, because the color singleton was irrelevant to the "dynamic change" that could be used to signal the target display's appearance, the DCOH also predicts no capture, as found by Lamy and Egeth. Thus, this absence of attentional capture is consistent with both hypotheses.

\section{Results Inconsistent With the DCOH and the CIOH: Capture Obtained}

We noted earlier that the $\mathrm{CIOH}$ and the $\mathrm{DCOH}$ cannot account for the results of the eight experiments reporting capture in Table A4. Although these results are inconsistent with both hypotheses, they cannot be construed as evidence for stimulus-driven attentional capture, because these results can be explained by observers adopting a singleton search (Bacon \& Egeth, 1994). In each of these eight experiments the target was a singleton; hence, observers could base their attentional control settings on a "singleton" feature to locate the target. In this case, any singleton (including the irrelevant and attention-capturing singleton) would be relevant to the attentional set. Accordingly, these results do not represent stimulus-driven capture, but rather contingent attentional capture effects.

For example, Chastain, Cheal, and Kuskova (2002, Experiments 1 and 2) presented target displays containing three Xs and one rotated $\mathrm{C}$. The target (rotated C) was the only curved item (a shape singleton), so observers could have adopted singleton search. The cue was a horizontal bar among vertical bars; hence, a static singleton. The cue was irrelevant to the target-localizing feature (shape) and to the displaywide "onset" of "white letters"; hence, the $\mathrm{CIOH}$ and the $\mathrm{DCOH}$ predict capture not to be observed, even though capture was obtained. The obtained capture effect can be explained by observers using a singleton search for the target (Bacon \& Egeth, 1994), because the target was a singleton. If a singleton search had been used, the attention-capturing singleton would have been relevant to the attentional set; hence, this result can be explained via top-down involvement.

Similarly, Lamy and Egeth's (2003, Experiments 1 and 5) capture effects can be accounted for by singleton search. Observers saw a fixation display containing six sets of shapes consisting of a triangle, a circle, a square, and a diamond, with each shape overlaid on the others. The target display's appearance was associated with the offset at each location of all except one of the overlaid shapes. The target was (randomly) the diamond, the square, or the triangle, whereas all of the nontargets were circles; hence, the target was a shape singleton. The cue was a color singleton irrelevant to the target-localizing feature (shape), so the $\mathrm{CIOH}$ predicts no capture. Because the color singleton was also irrelevant to the displaywide "offset" of shapes, the DCOH predicts no capture to be observed; however, Lamy and Egeth did observe capture, as is predicted by Bacon and Egeth's (1994) singleton-search hypothesis. Thus, Lamy and Egeth's results, as well as the results of the other experiments reporting capture in Table A4, can be explained by top-down involvement based on participants using a singleton search to find the target.

However, the claim that the capture effects in Cell IV are not evidence for stimulus-driven capture rests on the assumption that a singleton-search mode actually exists. As Theeuwes (2004) has recently suggested, Bacon and Egeth's (1994) failure to observe capture during feature search might have been due to higher perceptual load in their feature search displays than in their singleton search displays (cf. Lavie, 1995). Specifically, with several different shapes present, the feature search displays were heterogeneous compared with the homogenous singleton search displays that included one different shape. Theeuwes (2004) suggested that this heterogeneity could have reduced the salience and attention-capturing ability of the color singleton, due to the displays being "visually noisy." Also, because heterogeneity would have made target localization difficult, Theeuwes (2004) suggested that observers would have narrowed their attentional windows (like the "zoom lens"-Eriksen \& St. James, 1986; Eriksen \& Yeh, 1985) and focused on one item at a time so as to maintain accuracy. This would have precluded the color singleton from being simultaneously attended (perceived) with nonsingletons, and would have concealed its salience. To support these possibilities, Theeuwes (2004, Experiment 1) added circles to a feature search display, thereby presumably making them more homogeneous. Indeed, Theeuwes (2004) observed capture by a red color singleton during feature search for a green diamond. Theeuwes (2004) concluded that display heterogeneity, not feature search per se, caused Bacon and Egeth's failure to observe capture during feature search. Furthermore, he claimed that this result and his alternative explanation raises doubts as to the existence of singleton search and feature search modes.

However, Leber and Egeth (2006) noted that Theeuwes (2004) failed to take several important points into account 
in his analysis of Bacon and Egeth's (1994) experiments. This raises doubts about his reinterpretation of their results. First, in their feature-search conditions, Bacon and Egeth included displays in which the target was a singleton ( $1 / 3$ of trials). On these trials, because by Theeuwes's (2004) analysis the display was homogeneous, the color singleton should have been perceived as a salient singleton, but even in these displays the color singleton did not capture attention. This suggests that observers used a feature search, even on these trials, thereby precluding capture from the salient but irrelevant color singleton. Second, by adding circles to feature search displays, Theeuwes (2004) increased not only the color singleton's salience but also (to some degree) the target's salience. Thus, observers could have adopted a "salience-driven search" (akin to singleton search) for the target, which would have made the "salient" color singleton relevant to their attentional settings.

To demonstrate the existence of feature and singleton search modes, Leber and Egeth (2006) had observers in two groups search for a circle among squares. Because the displays were homogeneous, a color singleton should have been perceived as a salient singleton and should have captured attention in both groups (cf. Theeuwes, 2004). However, prior to this test phase, one group was trained to use a feature search for a circle among heterogeneous shapes (squares, diamonds, and triangles), whereas another group was trained to use a singleton search for an unpredictable shape (circle, triangle, or diamond) among all squares. Consistent with prior studies (Bacon \& Egeth, 1994; Lamy \& Egeth, 2003; Theeuwes, 1992, 2004), the training phase revealed capture by a color singleton in the singleton-search group, but not in the feature-search group. Solely on the basis of these results, it is impossible to differentiate between Bacon and Egeth's account and Theeuwes's (2004) account, because both predict this pattern of results. However, contrary to Theeuwes's (2004) account, this pattern of results was also observed in the test phase, even though the displays were homogeneous (and the color singleton salient) for both groups. Presumably, observers still used the feature-search mode they had been trained on even when a singleton-search mode could have been used in the test phase, thereby strongly supporting Bacon and Egeth's, and Leber and Egeth's, accounts. That is, feature-search training allowed observers to exert control over which stimulus to search for, thereby precluding capture by the irrelevant color singleton, whereas singleton search training made the color singleton relevant, thereby allowing it to capture attention. Most important, Leber and Egeth's results demonstrate that feature-search and singleton-search modes do exist.

As compelling as Leber and Egeth's (2006) results are, they used a somewhat indirect method for establishing the existence of the search modes by first training and then testing their participants. It could be that the featuresearch training induced a narrowed attentional window and the singleton-search training induced a wider attentional window (Theeuwes, 2004) that transferred over to the testing phase. If this occurred, the narrow attentional window in the test phase might have prevented the singleton from capturing attention in the group trained in feature search. ${ }^{7}$ However, this is unlikely for at least one reason: According to Theeuwes (2004), a narrowed attentional window is associated with a positive search slope. In other words, a narrow attentional window allows only one or two items to be processed at a time, rendering search serial or semiserial. However, the search slopes in Leber and Egeth's test phase were flat for the groups trained in both the feature search and the singleton search, suggesting that the attentional window was wide open. Thus, although Theeuwes's (2004) attentional-window account can explain the absence of capture in Leber and Egeth's feature-search training condition, it does not seem to explain the absence of capture in the test phase for that group; rather, that absence of capture must have been due to participants' use of a feature search. In sum, although Leber and Egeth used an indirect method, their results do seem to demonstrate the existence of both search modes.

Although the capture effects in Table A4 can be accounted for by singleton search, not every experiment in which singleton search could be utilized yielded capture (i.e., Chastain \& Cheal, 1998; Folk et al., 1994; Gibson \& Amelio, 2000; Pratt, Sekuler, \& McAuliffe, 2001; Rauschenberger, 2003b; Richard et al., 2003). However, these results do not undermine the claim that the capture effects in Table A4 can be accounted for by singleton search. Indeed, the experiments that reported capture presented singleton cues and targets within the same (static) perceptual dimension. For example, in Lamy and Egeth's (2003) Experiments 1 and 5, the cue was a color singleton and the target was a shape singleton. In contrast, for experiments not reporting capture, the cue was a static singleton but the target was a dynamic singleton. For example, Gibson and Amelio's cue was a color singleton and the target an onset singleton; hence, the feature difference between the cue and the target occurred across the perceptual dimensions. Thus, when singleton search can be used, capture does not seem to obtain when the cue and target differ across static and dynamic dimensions, at least when the target is dynamic and the cue static. In contrast, when the cue and the target are singletons within the same dimension, capture has been obtained.

\section{Cell IV Conclusion}

In line with the predictions of the $\mathrm{DCOH}$ and $\mathrm{CIOH}, 12$ experiments in Table A4 failed to yield capture effects. In these cases, an observer's attentional control settings appear to have prevented attention from being captured by an irrelevant singleton. However, inconsistent with both hypotheses, eight experiments in Table A4 yielded capture. Although these results could be construed as evidence for stimulus-driven capture based on the logic of the DCOH and of the $\mathrm{CIOH}$ alone, such a conclusion is inappropriate because the cues and targets were singletons. Thus, the results can be accounted for by a top-down influence via a singleton-search mode (Bacon \& Egeth, 1994), which Leber and Egeth (2006) convincingly demonstrated does exist, contrary to claims by Theeuwes (2004). However, just because singleton search accounts for some capture effects, and the DCOH cannot, does not mean that singleton search subsumes the DCOH. This is so because 
singleton search cannot account for capture when the target is not a singleton, but the DCOH can, in some cases. In short, although some capture cannot be explained by either the DCOH or the $\mathrm{CIOH}$, when Bacon and Egeth's singleton-search hypothesis is taken into account there is no conclusive evidence for a pure, stimulus-driven capture effect. I return to this point in the General Summary, when I discuss the apparent ecological invalidity of a system that does not allow attentional control settings to be overridden by salient but irrelevant stimuli.

\section{General Summary}

This review has applied Gibson and Kelsey's (1998; also Johnson et al.'s, 2001) DCOH to attention-capture experiments to demonstrate its importance for explaining capture in terms of top-down involvement above and beyond what can be explained by Folk et al.'s (1992) CIOH. Gibson and Kelsey stated that displaywide features associated with a display's appearance, not just features associated with the target itself, could comprise a person's attentional set and could mediate capture. Cues relevant to such a displaywide feature are predicted to capture attention, and such capture effects would represent contingent attentional capture effects.

So how important is the DCOH in explaining capture? From this review it is apparent that it accounts for every capture effect the $\mathrm{CIOH}$ explains as well as for nearly every other capture effect in the literature. Because the $\mathrm{DCOH}$ accounts for more results than the $\mathrm{CIOH}$ can, one may wonder whether the $\mathrm{CIOH}$ is even necessary. However, one positive aspect of the $\mathrm{CIOH}$ is that it can account for null capture effects in cases where the $\mathrm{DCOH}$ incorrectly predicts capture (Table A3). There are two responses to this. (1) Null effects should not be treated as genuine because of insufficient statistical power. By this account, the DCOH sufficiently accounts for all capture effects and the $\mathrm{CIOH}$ is not needed, not only because null effects should be discounted, but especially because many of them were obtained under conditions virtually identical to those that yielded the nonnull capture effects predicted by the DCOH. (2) Sometimes a target-relevant feature is more strongly represented in the attentional set than is some displaywide feature. In this case, the cue's relevance to that displaywide feature is weakly represented in the attentional set and overshadowed by the cue's irrelevance to a target-localizing feature strongly represented in the attentional set (but see Pratt \& McAuliffe, 2002). By this account, the $\mathrm{CIOH}$ should be considered when explaining null-capture effects that the DCOH incorrectly predicts should occur. However, until future research identifies those conditions in which the target-localizing feature will be more strongly represented in the attentional set than are the displaywide features, it seems prudent to conclude that the DCOH provides a sufficient account of capture effects and that the $\mathrm{CIOH}$ is not needed.

A conclusion that is at least as important is that when the abstract "singleton" feature comprises the attentional set, capture effects not accommodated by the DCOH or $\mathrm{CIOH}$ can be accounted for. Thus, all capture effects can be accounted for by top-down involvement. This is con- sistent with the view that conscious expectations and task requirements (top-down influences) influence the deployment of attention to relevant rather than irrelevant features in the visual field (Folk et al., 1993; Wolfe, 1994; Wolfe et al., 1989; Yantis, 1996, 1998). Hence, I know of no published evidence for capture based on purely stimulus-driven processes, and it remains for future research to uncover evidence for stimulus-driven capture effects. (However, see below.)

\section{Implications of the $\mathrm{DCOH}$ and Contingent Capture for Other Visual Phenomena}

Oculomotor capture. The shifting of the eyes toward a salient visual stimulus (oculomotor capture; Theeuwes \& Godijn, 2001; Theeuwes, Kramer, Hahn, \& Irwin, 1998) is inferred when the time to make a saccade from fixation to a target is slowed by the presence of a singleton distractor and/or when the saccade toward a target deviates from a straight line and "bends" toward the singleton. Such results indicate that the eyes, and not attention alone, are captured by salient stimuli. Because oculomotor-capture experiments use procedures and stimuli very similar to attentional capture experiments, oculomotor capture could also be mediated by one's attentional set. For example, Irwin et al. (2000) had observers make saccades to a color singleton circle and identify a letter inside. Observers first saw a display with four gray circles with a figure-eight placeholder inside each. The target display was revealed by changing the color of three gray circles to red and removing segments from the placeholders to create letters. Hence, a displaywide color change and dynamic change could have comprised the attentional set. Because the distractor was an onset singleton, it was relevant to the dynamic change associated with the target display's appearance; hence, the $\mathrm{DCOH}$ correctly predicts the capture that Irwin et al. observed.

Inhibition of return. Inhibition of return (IOR) is the finding that RTs are slower on cued than uncued targets when the cue-target SOA is $300 \mathrm{msec}$ or greater (Posner \& Cohen, 1984). IOR results from a reflexive shift of attention toward a cue followed by active suppression against returning attention to that cued location, which delays responding to cued targets. Because IOR is reflexive, some propose it as evidence for stimulus-driven capture (Pratt, Kingstone, \& Khoe, 1997; Pratt et al., 2001; Theeuwes $\&$ Godijn, 2002). However, there is a problem underlying this assumption, because IOR procedures are similar to attentional capture procedures, and because capture is presumably the precursor to IOR (attention must be captured for suppression to be applied). Indeed, if - as this review suggests - capture is not based on a reflexive and stimulus-driven process, it is likely that IOR is not stimulus driven, either. For example, in the seminal work of Posner and Cohen, an onset singleton target followed a transient luminance increase cue. In this case, the cue was featurally similar to the appearance of the target display because both were associated with "dynamic changes"; the DCOH can therefore account for the capture effect that Posner and Cohen found, which suggests that it can also account for the IOR observed by Posner and Cohen. 
Although the DCOH appears to account for IOR, there are instances in which a cue that is irrelevant to a targetlocalizing feature, but relevant to some other displaywide feature, did not elicit facilitation at a short SOA but produced IOR at a long SOA (Pratt \& McAuliffe, 2002). For example, when observers were set to respond to a color singleton target, Pratt and McAuliffe (2002) found an onset singleton elicited IOR (Experiments 2 and 3 ) but no observable facilitation (Experiment 1). (But see Gibson \& Amelio, 2000, and Pratt et al., 2001, for results inconsistent with those discussed here.) In each experiment, the onset-singleton cue was related to the "onset" of the target display stimuli; hence, the $\mathrm{DCOH}$ predicts capture at a short SOA and IOR at a long SOA. Although the IOR effect obtained by Pratt and McAuliffe (2002) can be accounted for by the DCOH, the presence of an IOR effect in the absence of capture at a shorter SOA is puzzling, because one would expect both IOR and capture to be elicited by the same cue and in the same situation. ${ }^{8}$

Pratt and McAuliffe's (2002; see also Theeuwes et al., 2000) potential explanation for this curious result, displayed in their Figure 5 (p. 1369), was that the absence of facilitation at the short SOA by the onset cue, which elicited IOR at the long SOA, was due to a rapid disengagement of attention from the onset-cued location. Specifically, it should be assumed that observers had attentional sets for "onset" and "color" because these features were relevant to detecting the target display and locating the target, respectively. The onset cue would have captured attention because it was relevant to detecting the target display's appearance. However, when observers shifted their attention to the onset cue's location and found that it was not the target, they would have quickly disengaged attention from (and inhibited) that location. This would have precluded facilitation from being observed at the short SOA, because attention would have been withdrawn from the onset-cued location prior to the target's appearance there on cued trials. In contrast, at the long SOA, if the color singleton was presented at the onset-cued location, attention would have been slow to return there because of the inhibition applied, which would produce IOR. As Pratt and McAuliffe (2002; p. 1368) noted, "the cue captures attention, but the attentional control setting produces a rapid disengagement of attention from the cue when it does not match the target." (This disengagement mechanism, introduced by Theeuwes et al., 2000, will be further discussed when I examine the ecological validity of a system based solely on contingent attentional capture.)

Attentional prioritization to abruptly onset ("new") objects. A consensus is that the onset of a new object (or a luminance change) receives attentional priority over nononset (static) items (Franconeri Hollingworth, \& Simons, 2005; Franconeri et al., 2004; Jonides \& Yantis, 1988; Posner, 1980; Theeuwes, 1994; J. T. Todd \& Van Gelder, 1979; Yantis, 1996, 1998, 2000; Yantis \& Jonides, 1984, 1990). Capture by onsets might, therefore, be stimulus driven; however, given this review, this might not be the case, because most target displays are associated with a dynamic change that could comprise the attentional set, leading the $\mathrm{DCOH}$ to predict capture by an abrupt onset, or a luminance change, both of which are defined as dynamic changes.

A recent study by Franconeri et al. (2004, Experiment 2) suggests that onsets might indeed enjoy a "special" status and elicit stimulus-driven capture. Franconeri et al. (2004) designed a clever experiment that eliminated the ability of observers to signal the target display's appearance with dynamic changes. Observers identified which of two letters appeared in a display that changed configuration from trial to trial. However, these configurations (dynamic changes) were not seen, because after responding on trial $n-1$, observers made a saccade to a point $33.4^{\circ}$ below the monitor. When their gaze reached that point, the letters on trial $n-1$ were reconfigured to those on trial $n$, such that all dynamic changes were unseen, and a dynamic cue should be irrelevant. After observers made a saccade back to fixation to begin target search, Franconeri et al. (2004) found that search was better when the target was cued by an abrupt onset of dots than when it was uncued or when no dots were presented. Franconeri et al. (2004) noted that, although capture by the onset cue could have been stimulus driven, observers might have used the onset cue to signal the start of visual search; this would explain their results. Indeed, although the display changes were unseen, upon returning to fixation observers might have set themselves to detect any "changes" from the previous trial to the current trial; the onset cue (a dynamic "change") would then have been relevant. Thus, it is unclear whether Franconeri et al.'s (2004) capture effects were truly stimulus driven.

\section{Testing the DCOH}

Because a target display must necessarily differ in some respect from the display that precedes it (otherwise this preceding display would be the target display), and because the DCOH can account for nearly every capture effect in the literature, whether or not the $\mathrm{DCOH}$ is unfalsifiable and, hence, untestable, is a question. It becomes crucial, therefore, to determine whether or not experiments can be designed that would allow a capture effect to be considered purely stimulus driven and unaccounted for by the $\mathrm{DCOH}$ (or by the $\mathrm{CIOH}$ and singleton search).

Only a few studies have tested the DCOH by addressing whether salient but irrelevant stimuli override attentional control settings for displaywide features (Atchley et al., 2000; Gibson \& Kelsey, 1998; Johnson et al., 2001). As the reader might have gathered from reading this review, it is very difficult to design an experiment so that the cue is totally irrelevant to an observer's attentional set, especially for all possible displaywide features. In order to rule out top-down involvement, an attention-capturing stimulus must be totally irrelevant to an observer's task-induced attentional set (instructions provided by the experimenter) and any attentional set that might be created by the observer (learned associations and strategies). The latter set creates the most problems, because one can never be sure of unintended strategies adopted by participants. Admittedly, such sets might not be created, but if the potential to create them exists, it introduces alternative explanations for observed capture effects. Below I discuss ways to demonstrate truly stimulus-driven capture with designs 
that will not allow an explanation based on top-down involvement.

Procedures used by Folk et al. (2002) provide a means to test for a stimulus-driven capture. Folk et al. (2002) observed capture from a peripheral distractor near a central rapid serial visual presentation (RSVP) stream of letters. Specifically, a red color singleton preceding a red target letter by $168 \mathrm{msec}$ caused accuracy to decrease in comparison with when a distractor was not being presented. By modifying this procedure, one could test for stimulusdriven capture from an onset singleton. To begin, two RSVP streams would be presented to ensure spatial uncertainty of the target's location, which is typical in capture experiments, compared with Folk et al.'s (2002) single stream that only induced temporal uncertainty of the target. Second, the target and all nontargets in each stream would be colored the same, so that the only feature useful for detecting the target would be its identity. Finally, prior to the target's appearance, an onset singleton would be presented near one stream. If accuracy were lower in this condition than when no distractor was presented, or if accuracy were higher when the onset singleton cued the stream with rather than without the target, one could assume that the onset singleton had captured attention. The DCOH would be unable to explain such a capture effect, because the "onset" of the cue would not comprise the attentional set. "Onset" is useless for locating the target and/or detecting its appearance because each letter in each stream is also associated with an onset; hence, establishing an attentional set on the basis of onset would cause observers to unnecessarily attend to each nontarget. Because such a capture effect could also not be explained by either the $\mathrm{CIOH}$ or by the singleton-search hypothesis, the onset singleton would be totally irrelevant to the attentional set; if a capture of attention occurred, it would be purely stimulus-driven.

However, it should be acknowledged that the RSVP task differs from a typical visual search task in that attention is usually focused on one location in the former, but is spread across several locations in the latter. Thus, comparing across these literatures is difficult, and can be somewhat misleading. ${ }^{9}$ One way to make the RSVP task more akin to visual search is to present several RSVP streams (even more than the two streams that I suggest above), so that attention must be distributed across visual space. Notwithstanding the important difference between these two tasks, I believe that RSVP could be modified so that the results of an attention-capture study using RSVP procedures (Folk et al., 2002) would be comparable to the results from the attention-capture studies that use visual search tasks.

Another example from our own lab (Neely \& Burnham, 2004) provides evidence of a static color discontinuity automatically capturing attention. Observers identified which of two targets appeared among three nontargets, with some of these stimuli colored red and others green. Prior to the appearance of this target display, a row of contiguous red Xs immediately adjacent to a contiguous line of green Xs, which together spanned the width of the screen, was presented. The location where the red
Xs "met" the green Xs formed a static color discontinuity that represented the cue. We found faster RTs to targets appearing near the color discontinuity than at some other location, suggesting that the discontinuity had captured attention. Because the target was not localized by a distinctive feature, the $\mathrm{CIOH}$ and singleton search cannot account for this result. Also, because the colors in the target display were the same as those in the cuing display, there was no color change that could be used to signal the target display's appearance. Hence, the color change at the static discontinuity was irrelevant, and the $\mathrm{DCOH}$ cannot account for this result. Because our result cannot be explained by top-down involvement, it represents a pure, stimulus-driven capture of attention by a color discontinuity.

Finally, the recently introduced surprise capture paradigm (Gibson \& Jiang, 1998; Horstmann, 2002, 2005) might provide a means for examining stimulus-driven capture from salient and unexpected stimuli. In this paradigm, participants complete a block of conjunctive search trials ( $n=48$ trials), in which they determine which of two targets appear among heterogeneous letters (e.g., an L or R among the letters P, B, K, N, S, H, T, I, E, J, and W). This is called a conjunctive search because it requires conjoining features that identify the target. On the trial immediately after this block (49th trial, surprise trial), the target appears as a unique singleton (typically a color singleton) and remains that way during the following block of $(n=$ 48) feature search trials. Participants complete all trials without breaks between the three segments (conjunctive search, surprise trial, feature search). If the "surprise" singleton captures attention, performance should be better on the surprise singleton trial than on the conjunctive search block, because attention will have been captured to the target's location.

As one example of this paradigm, Horstmann (2002, Experiment 3) had observers determine which of two targets appeared among different letters. During the conjunctive search block the letters were all white, and on the surprise trial and feature search trials the target was a color singleton among white letters. Horstmann (2002) assessed capture by varying the set size (4 vs. 12 items: between participants) to examine the search slope for each segment. If the singleton captured attention, the slope on the surprise trial should be less than the slope for the conjunctive search block and nearly equivalent to the slope for the feature search block. Indeed, the slope on the surprise trial $(12.5 \mathrm{msec} /$ item $)$ was less than the conjunctive search block (58.9 msec/item) and statistically equivalent to the feature search block (3.6 msec/item). This appears to be stimulus-driven capture because observers had no expectation for the irrelevant color singleton.

However, in inferring capture by comparing the surprise trial slope to the aggregate slope from the conjunctive search block, there is a limitation. Because performance might improve over the course of the conjunctive search trials, the slope on the trials immediately preceding the surprise trial would be shallower than would be the slope on the trials at the beginning of the conjunctive search block. Thus, to be sure the singleton captured attention, the 
surprise trial slope would have to be compared to the slope on the trial (or trials) immediately preceding it. ${ }^{10}$ If the slopes were equivalent, it would indicate that the singleton had not captured attention, and that the capture observed by Horstmann (2002) was due to search improving over the course of the trials, with the aggregate slope for the conjunctive search block being inflated due to inefficient search on the first few trials. Nevertheless, this paradigm might provide a new method to test for stimulus-driven capture, because the stimulus feature that produces the capture has not been previously relevant to localizing the target or to detecting the target display's appearance.

\section{Ecological Validity of Contingent Capture}

If salient and unexpected stimuli irrelevant to one's attentional control settings do not automatically capture attention, how could an organism survive? That is, if a contingency between a salient event and top-down expectations is required to elicit capture, potentially important and/or dangerous events would be ignored. A system that prevents salient stimuli from overriding attentional control settings would be detrimental to an organism, because priority could not be assigned to irrelevant but potentially dangerous stimuli. In contrast, a system allowing control settings to be overridden by stimuli that are discrepant from the control settings, or a system that initially assigns priority to all salient stimuli, would greatly benefit an organism and be much more pragmatic and ecologically valid than a system relying on contingencies for capture to be elicited. But if such a stimulus-driven system existed, how could it account for the absence of evidence for stimulus-driven capture effects? To answer this, I discuss what top-down mediation means in relation to stimulusdriven capture, and delineate how stimulus-driven capture could be elicited, but be overshadowed by contingent capture effects. I then describe and elaborate on a mechanism introduced by Theeuwes et al. (2000) that does not prevent irrelevant stimuli from capturing attention but that precludes observing stimulus-driven capture effects by rapidly removing attention from salient but irrelevant visual stimuli.

To begin, recall that proponents of contingent-capture theories state that a stimulus will capture attention if it is relevant to a person's attentional control settings. By this account, control settings mediate capture, but this does not necessarily mean that they cause capture or that they prevent salient but irrelevant stimuli from initially capturing attention automatically. To understand this issue, it may be useful to consider the analogous issue of automatic spreading activation as a mechanism that produces semantic priming (Neely, 1991; Posner \& Snyder, 1975). As discussed by Neely and Kahan (2001), even if a semantic priming effect does not occur, it does not mean that semantic activation is not automatic. For example, semantic activation might automatically occur when a prime is presented, but activation might have decayed by the time a related target was presented so that priming was not observed, even though the prime automatically activated its semantic properties. Moreover, an automatic (stimulus-driven) process can be moderated by top-down processes (Neely \& Kahan, 2001). For example, the effects of activation spreading between memory nodes for a related prime and target can be amplified by a top-down expectancy for targets being related to the prime, or they can be offset by the countervailing effect of the person expecting the target to be unrelated to the prime. (See Neely, 1977, for examples.) In an analogous vein, merely showing that attentional capture is influenced by top-down attentional settings does not mean that it cannot also be stimulus driven. That is, stimulus-driven capture could be automatically elicited by salient but irrelevant stimuli, but the effect could be overshadowed by contingent attentional capture by relevant stimuli. Indeed, contingent capture effects may merely indicate that relevant stimuli are attended to more than are irrelevant stimuli, and not that stimulus-driven capture by an irrelevant stimulus was totally prevented and did not occur at all.

Theeuwes et al. (2000) proposed a mechanism that could account for more attention being allocated to relevant stimuli and less to irrelevant stimuli, which would result in stimulus-driven capture being overshadowed by contingent capture. According to Theeuwes et al. (2000), salient stimuli (relevant and irrelevant) automatically capture attention on the basis of their physical salience alone (stimulus-driven capture). After attention is captured, attentional control settings determine whether attention is to be allocated (engaged) to, or disengaged from, each attention-capturing stimulus (see also Lamy, 2005; Pratt $\&$ McAuliffe, 2002). Thus, contrary to Folk et al. (1992), who proposed that attentional control settings reconfigure the attentive system to allow only salient stimuli to capture attention, Theeuwes et al. (2002) suggested that these settings "kick in" only after attention has been captured. Only then are the attention-capturing stimuli compared with the attentional set and their relevance determined. This makes sense, because determining relevance requires a stimulus to be compared with an attentional set, which presumably requires attention to that stimulus. Because this attentional allocation occurs prior to a stimulus' relevance being determined, the initial capture of attention by the "unknown" stimulus must be stimulus driven.

For example, suppose that someone has an attentional set for "red." If an onset singleton were presented, it would (according to Theeuwes et al., 2000) capture attention on the basis of its salience alone, but attention would be quickly disengaged when it was determined that the onset singleton was irrelevant. This disengagement occurs quickly (and prior to a target's appearance) so as to conserve attentional resources. Because attention is disengaged prior to the target's appearance, the stimulus-driven capture of attention by the onset singleton will not be observed. This is so because after attention is disengaged it will likely return to fixation, and attention will have to travel the same distance to a cued target or an uncued target, which will result in equivalent RTs and no observable capture effect.

Now consider a red color singleton being presented. In this case, attention is captured on the basis of the color singleton's salience; however, instead of being quickly disengaged, attention will remain at the red color singleton's location once it is determined to be relevant. This would 
facilitate RTs to targets presented at that location, thereby producing an observable capture effect. This would be a contingent capture effect, because - although the initial capture was stimulus driven and due to salience alonethe observed effect of this capture was contingent on the cue being relevant and on more attention being allocated to it. In short, stimulus-driven capture may be so shortlived that at cue-target SOAs of around $150-250 \mathrm{msec}$, attention is disengaged from an irrelevant but attentioncapturing cue, thereby precluding any observable effect.

In sum, salient but irrelevant stimuli could automatically capture attention without producing an observable capture effect if attention were quickly disengaged from such a stimulus (Pratt \& McAuliffe, 2002; Theeuwes et al., 2000). Such disengagement makes sense if attentional resources are to be conserved so as to allow processing priority to be given to relevant stimuli. Indeed, if attention were not disengaged, the processing of irrelevant stimuli would consume attentional resources, and would interfere with the processing of relevant stimuli. Although it has received little research attention, by suggesting that both effects can occur in the same setting and at the same time (just as automatic and expectancy-based priming mechanisms do), the disengagement mechanism proposed by Theeuwes et al. (2000) might offer a viable compromise between proponents of stimulus-driven attentional capture and proponents of contingent attentional capture. Clearly, future research should investigate this possibility.

\section{Conclusions}

At least six important points emerge from this review. (1) Gibson and Kelsey's (1998) DCOH accounts for nearly every capture effect reported in the literature, including all of those that Folk et al.'s (1992) CIOH can explain. (2) Although the DCOH accounts for all capture that can be explained by the $\mathrm{CIOH}$, the opposite is not true; therefore, the $\mathrm{DCOH}$ accounts for more results than does the $\mathrm{CIOH}$. (3) If some of the null capture effects obtained when the $\mathrm{DCOH}$ predicts nonnull effects are genuine, the $\mathrm{CIOH}$ may be essential for interpreting the full array of results reported in the capture literature; however, I believe that until the conditions under which genuine null effects are obtained are clearly delineated, it is more accurate to conclude that capture effects purported to support the $\mathrm{CIOH}$ actually support the DCOH. (4) All capture effects that have been obtained when neither the DCOH nor $\mathrm{CIOH}$ could predict them occurred when observers could have been using a singleton-search mode, which is yet another type of top-down (contingent) capture effect. (5) Perhaps most important, because all instances of capture in the literature are contingent, in that they can be explained by top-down involvement, there currently is no compelling evidence for attentional capture that is purely stimulus driven. (The one exception may be found in an as-yetunpublished experiment reported by Neely \& Burnham, 2004.) (6) A system based on top-down influences being necessary to elicit capture is not ecologically valid; hence, it is possible that a salient, distinctive stimulus will always capture attention in a stimulus-driven fashion, but that some sort of disengagement mechanism kicks in after this stimulus-driven capture has occurred, thereby concealing its occurrence.

I believe the take-home message from this review is as follows: In any experiment, it is likely that displaywide features useful in alerting participants to the target display's appearance can comprise the attentional set. Hence, to infer that a capture effect was not due to top-down involvement it is not sufficient simply to make the cue irrelevant to all features that can be used to locate the target within the target display; rather, one must ensure that the cue is irrelevant to features that could comprise the attentional set, because they can be used to signal the target display's appearance. Indeed, for all published experiments reporting capture, the feature that made the attention-capturing cue distinctive was likely in the attentional set, because it was informative concerning the target display's appearance. Therefore, all published capture effects of which I am aware were the result of contingent captures of attention. However, this does not mean that stimulus-driven capture does not exist, and it may very well be that stimulus-driven and top-down capture effects occur simultaneously. Hence, the challenge for future research is to use designs that provide a pure measure of stimulus-driven capture effects, without the contaminating effects of top-down influences, so that stimulus-driven capture effects can be revealed - if indeed they do exist, as seems likely on the basis of ecological and evolutionary considerations.

\section{AUTHOR NOTE}

An early version of this review was submitted to the faculty at the University at Albany for the qualifying exam requirement in partial fulfillment of the $\mathrm{PhD}$ in cognitive psychology. I thank my qualifying exam committee-Jim Neely, Tram Neill, and Frank Vellutino-for helpful comments and encouragement. I also thank Don Graves, Jeff Johnson, Jay Pratt, Jan Theeuwes, Pete Walker, and two anonymous reviewers for helpful comments and insight regarding the ideas put forth in earlier versions of this review. Correspondence regarding this article should be addressed to B. R. Burnham, now at the Department of Psychology (AMH), University of Scranton, Scranton, PA 18510 (e-mail: attention .perform@gmail.com).

\section{REFERENCES}

Abrams, R. A., \& Christ, S. E. (2003). Motion onset captures attention. Psychological Science, 14, 427-432.

Ansorge, U., \& Heumann, M. (2003). Top-down contingencies in peripheral cuing: The roles of color and location. Journal of Experimental Psychology: Human Perception \& Performance, 29, 937-948.

Atchley, P., Kramer, A. F., \& Hillstrom, A. (2000). Contingent capture for onsets and offsets: Attention set for perceptual transients. Journal of Experimental Psychology: Human Perception \& Performance, 26, 594-606.

Bacon, W., \& Egeth, H. (1994). Overriding stimulus-driven attentional capture. Perception \& Psychophysics, 55, 485-496.

Bravo, M. J., \& NaKayama, K. (1992). The role of attention in different visual-search tasks. Perception \& Psychophysics, 51, 465-472.

Broadbent, D. E. (1958). Perception and communication. Elmsford, NY: Pergamon.

Chastain, G., \& Cheal, M. (1998). Automatic versus directed attention with single-element and multiple-element precues. Visual Cognition, 5, 339-364.

Chastain, G., \& Cheal, M. (2001). Attentional capture with various distractor and target types. Perception \& Psychophysics, 63, 979-990.

Chastain, G., \& Cheal, M., \& Kuskova, V. (2002). Inappropri- 
ate capture by diversionary dynamic elements. Visual Cognition, $\mathbf{9}$, 355-381.

Egeth, H. E. (1977). Attention and preattention. In G. H. Bower (Ed.), The psychology of learning and motivation (Vol. 7, pp. 277-320). San Diego: Academic Press.

Enns, J. T., Austen, E. L., Di Lollo, V., Rauschenberger, R., \& YANTIS, S. (2001). New objects dominate luminance transients in setting attentional priority. Journal of Experimental Psychology: Human Perception \& Performance, 27, 1287-1302.

ErIKsen, C. W., \& St. James, J. D. (1986). Visual attention within and around the field of focal attention: A zoom lens model. Perception \& Psychophysics, 40, 225-240.

ERIKSEN, C. W., \& YEH, Y. Y. (1985). Allocation of attention in the visual field. Journal of Experimental Psychology: Human Perception \& Performance, 11, 583-597.

FolK, C. L., \& AnNeTt, S. (1994). Do locally defined feature discontinuities capture attention? Perception \& Psychophysics, 56, 277-287.

Folk, C. L., Leber, A. B., \& Egeth, H. E. (2002). Made you blink! Contingent attentional capture produces a spatial blink. Perception \& Psychophysics, 64, 741-753.

FolK, C. L., \& Remington, R. W. (1996). When knowledge does not help: Limitations on the flexibility of attentional control. In A. F. Kramer, M. G. M. Coles, \& G. D. Logan (Eds.), Converging operations in the study of visual selective attention (pp. 271-295). Washington, DC: American Psychological Association.

FolK, C. L., \& Remington, R. W. (1998). Selectivity in distraction by irrelevant featural singletons: Evidence for two forms of attentional capture. Journal of Experimental Psychology: Human Perception \& Performance, 24, 847-858.

Folk, C. L., \& Remington, R. [W.] (1999). Can new objects override attentional control settings? Perception \& Psychophysics, 61, 727-739.

Folk, C. L., Remington, R. W., \& Johnston, J. C. (1992). Involuntary covert orienting is contingent on attentional control settings. Journal of Experimental Psychology: Human Perception \& Performance, 18 1030-1044.

Folk, C. L., Remington, R. W., \& Johnston, J. C. (1993). Contingent attentional capture: A reply to Yantis (1993). Journal of Experimental Psychology: Human Perception \& Performance, 19, 682-685.

Folk, C. L., Remington, R. W., \& Wright, J. H. (1994). The structure of attentional control: Contingent attentional capture by apparent motion, abrupt onset, and color. Journal of Experimental Psychology: Human Perception \& Performance, 20, 317-329.

Franconeri, C. M., Hollingworth, A., \& Simons, D. J. (2005). Do new objects capture attention? Psychological Science, 16, 275-281.

Franconeri, S. L., \& Simons, D. J. (2003). Moving and looming stimuli capture attention. Perception \& Psychophysics, 65, 999-1010.

Franconeri, S. L., Simons, D. J., \& Junge, J. A. (2004). Searching for stimulus-driven shifts of attention. Psychonomic Bulletin \& Review, 11, 876-881.

Gibson, B. S. (1996).Visual quality and attentional capture: A challenge to the special role of abrupt onsets. Journal of Experimental Psychology: Human Perception \& Performance, 22, 1496-1504.

Gibson, B. S., \& AMELIO, J. (2000). Inhibition of return and attentional control settings. Perception \& Psychophysics, 62, 496-504.

Gibson, B. S., \& Jiang, Y. (1998). Surprise! An unexpected color singleton does not capture attention in visual search. Psychological Science, 9, 176-182.

Gibson, B. S., \& Kelsey, E. M. (1998). Stimulus-driven attentional capture is contingent on attentional set for displaywide visual features. Journal of Experimental Psychology: Human Perception \& Performance, 24, 699-706.

Hickey, C., McDonald, J. J., \& Theeuwes, J. (2006). Electrophysiological evidence of the capture of visual attention. Journal of Cognitive Neuroscience, 18, 604-613.

Hillstrom, A. P., \& Yantis, S. (1994). Visual motion and attentional capture. Perception \& Psychophysics, 55, 399-411.

HorstmanN, G. (2002). Evidence for attentional capture by a surprising color singleton in visual search. Psychological Science, 13, 499-505.

Horstmann, G. (2005). Attentional capture by an unannounced color singleton depends on expectation discrepancy. Journal of Experimental Psychology: Human Perception \& Performance, 31, 1039-1060.

Irwin, D. E., Colcombe, A. M., Kramer, A. F., \& Hahn, S. (2000).
Attentional and oculomotor capture by onset, luminance and color singletons. Vision Research, 40, 1443-1458.

Johnson, J. D., Hutchison, K. A., \& Neill, W. T. (2001). Attentional capture by irrelevant color singletons. Journal of Experimental Psychology: Human Perception \& Performance, 27, 841-847.

JONIDES, J. (1981). Voluntary vs. automatic control over the mind's eye's movement. In J. [B.] Long \& A. [D.] Baddeley (Eds.), Attention and performance IX (pp. 187-203). Hillsdale, NJ: Erlbaum.

Jonides, J., \& YANTIS, S. (1988). Uniqueness of abrupt visual onset in capturing attention. Perception \& Psychophysics, 43, 346-354.

JosePh, J. S., \& Optican, L. M. (1996). Involuntary attentional shifts due to orientation differences. Perception \& Psychophysics, 58, 651-665.

Juola, J. F., Koshino, H., \& Warner, C. B. (1995). Tradeoffs between attentional effects of spatial cues and abrupt onsets. Perception \& Psychophysics, 57, 333-342.

Kahneman, D., Treisman, A., \& Burkell, J. (1983). The cost of visual filtering. Journal of Experimental Psychology: Human Perception \& Performance, 9, 510-522.

KIM, M.-S., \& CAVE, K. R. (1999). Top-down and bottom-up attentional control: On the nature of interference from a salient distractor. Perception \& Psychophysics, 61, 1009-1023.

KIM, M.-S., \& CAVE, K. R. (2001). Perceptual grouping via spatial selection in a focused-attention task. Vision Research, 41, 611-624.

Lambert, A., Spencer, E., \& Mohindra, N. (1987). Automaticity and the capture of attention by a peripheral display change. Current Psychological Research \& Reviews, 6, 136-147.

LAMY, D. (2005). Temporal expectations modulate attentional capture. Psychonomic Bulletin \& Review, 12, 1112-1119.

LAmy, D., \& Egeth, H. E. (2003). Attentional capture in singletondetection and feature-search modes. Journal of Experimental Psychology: Human Perception \& Performance, 29, 1003-1020.

LAmy, D., Leber, A., \& EgETH, H. E. (2004). Effects of task relevance and stimulus-driven salience in feature-search mode. Journal of Experimental Psychology: Human Perception \& Performance, 30, 1019-1031.

Lamy, D., Tsal, Y., \& Egeth, H. E. (2003). Does a salient distractor capture attention early in processing? Psychonomic Bulletin \& Review, 10, 621-629.

Lavie, N. (1995). Perceptual load as a necessary condition for selective attention. Journal of Experimental Psychology: Human Perception \& Performance, 21, 451-468.

Leber, A. B., \& Egeth, H. E. (2006). It's under control: Top-down search strategies can override attentional capture. Psychonomic Bulletin \& Review, 13, 132-138.

Martin-Emerson, R., \& Kramer, A. F. (1997). Offset transients modulate attentional capture by sudden onsets. Perception \& Psychophysics, 59, 739-751.

Miller, J. (1989). The control of attention by abrupt visual onsets and offsets. Perception \& Psychophysics, 45, 567-571.

NeELy, J. H. (1977). Semantic priming and retrieval from lexical memory: Roles of inhibitionless spreading activation and limitedcapacity attention. Journal of Experimental Psychology: General, 106, 226-254

NeELY, J. H. (1991). Semantic priming effects in visual word recognition: A selective review of current findings and theories. In D. Besner \& G. W. Humphreys (Eds.), Basic processes in reading: Visual word recognition (pp. 264-336). Hillsdale, NJ: Erlbaum.

Neely, J. H., \& Burnham, B. R. (2004, November). A noncontingent, automatic capture of spatial attention by a static discontinuity. Paper presented at the 45th Annual Meeting of the Psychonomic Society, Minneapolis, MN.

NeEly, J. H., \& KaHAN, T. A. (2001). Is semantic activation automatic? A critical re-evaluation. In H. L. Roediger III, J. S. Nairne, I. Neath, \& A. M. Surprenant (Eds.), The nature of remembering: Essays in honor of Robert G. Crowder (pp. 69-93). Washington, DC: American Psychological Association.

NeISSER, U. (1963). Decision-time without reaction-time: Experiments in visual scanning. American Journal of Psychology, 76, 376-385.

PAshler, H. (1988). Cross-dimensional interaction and texture segregation. Perception \& Psychophysics, 43, 307-318.

Peterson, M. S., \& Kramer, A. F. (2001). Contextual cueing reduces 
interference from task-irrelevant onset distractors. Visual Cognition, 8, 843-859.

Posner, M. I. (1980). Orienting of attention. Quarterly Journal of Experimental Psychology, 32, 3-25.

Posner, M. I., \& Cohen, Y. (1984). Components of visual orienting. In H. Bouma \& D. G. Bouwhuis (Eds.), Attention and performance $X$ (pp. 531-556). Hillsdale, NJ: Erlbaum.

Posner, M. I., \& SNyder, C. R. R. (1975). Attention and cognitive control. In R. L. Solso (Ed.), Information processing and cognition: The Loyola symposium (pp. 55-83). Hillsdale, NJ: Erlbaum.

Posner, M. I., Snyder, C. R. R., \& Davidson, B. J. (1980). Attention and the detection of signals. Journal of Experimental Psychology: General, 109, 160-174.

Pratt, J., Kingstone, A., \& Khoe, W. (1997). Inhibition of return in location- and identity-based choice decision tasks. Perception \& Psychophysics, 59, 964-971.

Pratt, J., \& McAuliffe, J. (2001). The effects of onsets and offsets on visual attention. Psychological Research, 65, 185-191.

Pratt, J., \& McAuliffe, J. (2002). Determining whether attentional control settings are inclusive or exclusive. Perception \& Psychophysics, 64, 1361-1370.

Pratt, J., Sekuler, A. B., \& McAuliffe, J. (2001). The role of attentional set on attentional cueing and inhibition of return. Visual Cognition, 8, 33-46.

RAuschenberger, R. (2003a). Attentional capture by auto- and allocues. Psychonomic Bulletin \& Review, 10, 814-842.

RAUSCHENBERGER, R. (2003b). When something old becomes something new: Spatiotemporal object continuity and attentional capture. Journal of Experimental Psychology: Human Perception \& Performance, 29, 600-615.

Remington, R. W., Folk, C. L., \& McLean, J. P. (2001). Contingent attentional capture or delayed allocation of attention? Perception \& Psychophysics, 63, 298-307.

Remington, R. W., Johnston, J. C., \& Yantis, S. (1992). Involuntary attentional capture by abrupt onsets. Perception \& Psychophysics, 51, 279-290.

Richard, C. M., Wright, R. D., \& WARD, L. M. (2003). Goal-driven modulation of stimulus-driven attentional capture in multiple-cue displays. Perception \& Psychophysics, 65, 939-955.

Riggio, L., Bello, A., \& Umiltà, C. (1998). Inhibitory and facilitatory effects on cue onset and offset. Psychological Research, 61, 107-118.

SAmuel, A. G., \& Weiner, S. K. (2001). Attentional consequences of object appearance and disappearance. Journal of Experimental Psychology: Human Perception \& Performance, 27, 1433-1451.

Simons, D. J. (2000). Attentional capture and inattentional blindness. Trends in Cognitive Sciences, 4, 147-155.

SNOWDEN, R. J. (2002). Visual attention to color: Parvocellular guidance of attentional resources? Psychological Science, 13, 180-184.

SNOWden, R. J., Willey, J., \& MuIR, J. L. (2001). Visuospatial attention: The role of target contrast and task difficulty when assessing the effects of cues. Perception, 30, 983-991.

Theeuwes, J. (1990). Perceptual selectivity is task-dependent: Evidence from selective search. Acta Psychologica, 74, 81-99.

Theeuwes, J. (1991a). Cross-dimensional perceptual selectivity. Perception \& Psychophysics, 50, 184-193.

TheEUwES, J. (1991b). Exogenous and endogenous control of visual attention: The effect of visual onsets and offsets. Perception \& Psychophysics, 49, 83-90.

Theeuwes, J. (1992). Perceptual selectivity for color and form. Perception \& Psychophysics, 51, 599-606.

Theeuwes, J. (1994). Stimulus-driven capture and attentional set: Selective search for color and visual abrupt onsets. Journal of Experimental Psychology: Human Perception \& Performance, 20, 799-806.

Theeuwes, J. (1996). Perceptual selectivity for color and form: On the nature of the interference effect. In A. F. Kramer, M. G. M. Coles, \& G. D. Logan (Eds.), Converging operations in the study of visual selective attention (pp. 297-314). Washington, DC: American Psychological Association.

Theeuwes, J. (2004). Top-down search strategies cannot override attentional capture. Psychonomic Bulletin \& Review, 11, 65-70.

Theeuwes, J., Atchley, P., \& Kramer, A. F. (2000). On the time course of top-down and bottom-up control of visual attention. In S. Monsell
\& J. Driver (Eds.), Control of cognitive processes: Attention and performance XVIII (pp. 105-124). Cambridge, MA: MIT Press.

Theeuwes, J., \& Burger, R. (1998). Attentional control during visual search: The effect of irrelevant singletons. Journal of Experimental Psychology: Human Perception \& Performance, 24, 1342-1353.

Theeuwes, J., \& Chen, C. Y. D. (2005). Attentional capture and inhibition (of return): The effect on perceptual sensitivity. Perception \& Psychophysics, 67, 1305-1312.

Theeuwes, J., De Vries, G. J., \& GodiJn, R. (2003). Attentional and oculomotor capture with static singletons. Perception \& Psychophysics, 65, 735-746.

Theeuwes, J., \& Godisn, R. (2001). Attentional and oculomotor capture. In B. S. Gibson \& C. L. Folk (Eds.), Attraction, distraction and action: Multiple perspectives on attentional capture (pp. 121-149). New York: Elsevier Science.

Theeuwes, J., \& Godisn, R. (2002). Irrelevant singletons capture attention: Evidence from inhibition of return. Perception \& Psychophysics, 64, 764-770.

Theeuwes, J., Kramer, A. F., Hahn, S., \& Irwin, D. E. (1998). Our eyes do not always go where we want them to go: Capture of the eyes by new objects. Psychological Science, 9, 379-385.

Theeuwes, J., Kramer, A. F., Hahn, S., Irwin, D. E., \& Zelinsky, G. J. (1999). Influence of attentional capture on oculomotor control. Journal of Experimental Psychology: Human Perception \& Performance, 25, 1595-1608.

Theeuwes, J., Kramer, A. F., \& Kingstone, A. (2004). Attentional capture modulates perceptual sensitivity. Psychonomic Bulletin \& Review, 11, 551-554.

TodD, J. T., \& VAN GELdER, P. (1979). Implications of a transientsustained dichotomy for the measurement of human performance. Journal of Experimental Psychology: Human Perception \& Performance, 5, 625-638.

TodD, S., \& Kramer, A. F. (1994). Attentional misguidance in visual search. Perception \& Psychophysics, 56, 198-210.

Treisman, A. M. (1969). Strategies and models of selective attention. Psychological Review, 76, 282-299.

Treisman, A. M., \& Gelade, G. (1980). A feature-integration theory of attention. Cognitive Psychology, 12, 97-136.

Treisman, A. [M.], Kahneman, D., \& Burkell, J. (1983). Perceptual objects and the cost of filtering. Perception \& Psychophysics, 33, 527-532.

Treisman, A. [M.], \& Souther, J. (1985). Search asymmetry: A diagnostic for preattentive processing of separable features. Journal of Experimental Psychology: General, 114, 285-310.

Turatto, M., \& Galfano, G. (2000). Color, form and luminance capture attention in visual search. Vision Research, 40, 1639-1643.

Turatto, M., \& Galfano, G. (2001). Attentional capture by color without any relevant attentional set. Perception \& Psychophysics, 63, 286-297.

Turatto, M., Galfano, G., Gardini, S., \& Mascetti, G. G. (2004). Stimulus-driven attentional capture: An empirical comparison of display-size and distance methods. Quarterly Journal of Experimental Psychology, 57A, 297-324.

Wolfe, J. M. (1994). Guided Search 2.0: A revised model of visual search. Psychonomic Bulletin \& Review, 1, 201-238.

Wolfe, J. M. (1998). What can 1 million trials tell us about visual search? Psychological Science, 9, 33-39.

Wolfe, J. M. (2001). Asymmetries in visual search: An introduction. Perception \& Psychophysics, 63, 381-389.

Wolfe, J. M., Butcher, S. J., Lee, C., \& Hyle, M. (2003). Changing your mind: On the contributions of top-down and bottom-up guidance in visual search for feature singletons. Journal of Experimental Psychology: Human Perception \& Performance, 29, 483-502.

Wolfe, J. M., Cave, K. R., \& Franzel, S. L. (1989). Guided search: An alternative to the feature integration model for visual search. Journal of Experimental Psychology: Human Perception \& Performance, 15, 419-433.

Wright, R. D., \& Richard, C. M. (2003). Sensory mediation of stimulus-driven attentional capture in multiple-cue displays. Perception \& Psychophysics, 65, 925-938.

Wu, S. C., \& Remington, R. W. (2003). Characteristics of covert and overt visual orienting: Evidence from attentional and oculomotor 
capture. Journal of Experimental Psychology: Human Perception \& Performance, 29, 1050-1067.

YANTIS, S. (1993). Stimulus-driven attentional capture and attentional control settings. Journal of Experimental Psychology: Human Perception \& Performance, 19, 676-681.

Yantis, S. (1996). Attentional capture in vision. In A. F. Kramer, M. G. M. Coles, \& G. D. Logan (Eds.), Converging operations in the study of visual selective attention (pp. 45-76). Washington, DC: American Psychological Association.

YANTIS, S. (1998). Objects, attention, and perceptual experience. In R. D. Wright (Ed.), Visual attention (pp. 187-214). New York: Oxford University Press.

YANTIS, S. (2000). Goal-directed and stimulus-driven determinants of attentional capture (tutorial). In S. Monsell \& J. Driver (Eds.), Control of cognitive processes: Attention and performance XVIII (pp. 73-103). Cambridge, MA: MIT Press.

YAntis, S., \& EGETH, H. E. (1999). On the distinction between visual salience and stimulus-driven attentional capture. Journal of Experimental Psychology: Human Perception \& Performance, 25, 661-676.

YANTIS, S., \& Hillstrom, A. P. (1994). Stimulus-driven attentional capture: Evidence from equiluminant visual objects. Journal of Experimental Psychology: Human Perception \& Performance, 20, 95-107.

Yantis, S., \& Jonides, J. (1984). Abrupt visual onsets and selective attention: Evidence from visual search. Journal of Experimental Psychology: Human Perception \& Performance, 10, 610-621.

YANTIS, S., \& Jonides, J. (1990). Abrupt visual onsets and selective attention: Voluntary versus automatic allocation. Journal of Experimental Psychology: Human Perception \& Performance, 16, 121-134.

YANTIS, S., \& JoNIDES, J. (1996). Attentional capture by abrupt onsets: New perceptual objects or visual masking? Journal of Experimental Psychology: Human Perception \& Performance, 22, 1505-1513.

\section{NOTES}

1. Folk and Remington (1998) suggested distractor interference could be due to a difficulty in processing displays containing a singleton distractor versus those without one, rather than due to the distractor physically drawing attention to its location. That is, the presence of a distractor may consume nonspatial attentional resources and may delay responding to the target, as opposed to when the distractor is absent (Kahneman, Treisman, \& Burkell, 1983; Treisman, Kahneman, \& Burkell, 1983); this mimics attentional capture. Such an effect has been called a filtering cost. However, Theeuwes, Kramer, and Kingstone (2004; see also
Theeuwes \& Chen, 2005) found that interference was greatest when the singleton distractor was far from the target and smallest when it was near the target. Hence, interference varied as a function of spatial distance between the target and distractor, suggesting that distractor interference reflects a capture of spatial attention. Recent electrophysiological evidence supports this view (e.g., Hickey, McDonald, \& Theeuwes, 2006).

2. Leber and Egeth (2006) demonstrated that after observers practiced searching for a target in a feature search condition, a singleton distractor did not capture attention even when observers could now use a singleton search. This was presumably due to observers continuing to search for the target-relevant features even when singleton search could have been used. This point will be thoroughly discussed later in the review.

3. Theeuwes (2004) demonstrated that Bacon and Egeth's (1994) failure to observe capture during feature search might have been due to the shape heterogeneity in the target display, which decreased the singleton distractor's salience. Theeuwes found that by increasing the number of repeated shapes in the display, which increased the display's homogeneity, a color singleton now captured attention even though feature search was required. Theeuwes (2004) concluded that with a heterogeneous display observers were forced to narrow their attention to focus on one item at a time while they searched serially for the target. This narrowing of attention maintains accuracy but prevents the singleton from being simultaneously attended with other items, which conceals its status as a salient "singleton," thereby preventing it from capturing attention. This point will be readdressed later in this review.

4. For this review, Bacon and Egeth's (1994) singleton search hypothesis will not be subsumed by the CIOH (Folk et al., 1992). This is because although singleton search requires the target to be a "singleton," the $\mathrm{CIOH}$ requires only that the target's location be designated by some unique feature. Indeed, this point will become especially important later in the review when I discuss how some results that cannot be explained by the $\mathrm{CIOH}$ can be explained by a singleton search.

5. The number of experiments summarized in this review is fewer than 301 , because many authors not investigating attentional capture cite Folk et al. (1992) as a reference providing evidence for expectancy affecting the allocation of attention.

6. I thank an anonymous reviewer for suggesting that observers in Abrams and Christ's (2003) Experiment 1 could have formed an attentional set for motion onset due to its being more salient than the other motion items.

7. I thank Jan Theeuwes for pointing this out.

8. I thank Jay Pratt for pointing this out.

9. I thank Jan Theeuwes for pointing this out.

10. I thank Tram Neill for pointing this out. 


\section{APPENDIX}

Table A1

Experiments in Which Both the DCOH and the CIOH Predict Attentional Capture

\begin{tabular}{|c|c|c|c|c|c|}
\hline Experiment & Target & Target Display Features & Cue Feature & Miscellaneous & Effect \\
\hline \multicolumn{6}{|c|}{ Spatial Precuing Experiments } \\
\hline $\begin{array}{l}\text { Ansorge \& Heumann } \\
\quad(2003, \text { Exp. 1) }\end{array}$ & S-onset & $\begin{array}{l}\text { S-onset of red or green circle } \\
\text { (color blocked) }\end{array}$ & $\begin{array}{l}\text { S-onset (similar color } \\
\text { to target) }\end{array}$ & & $39 \mathrm{msec}^{*}$ \\
\hline $\begin{array}{l}\text { Ansorge \& Heumann } \\
\quad(2003 \text {, Exp. 2) }\end{array}$ & S-onset & $\begin{array}{l}\text { S-onset of red or green circle } \\
\text { (color varied) }\end{array}$ & $\begin{array}{l}\text { S-onset (similar color } \\
\text { to target) }\end{array}$ & & $18 \mathrm{msec}^{*}$ \\
\hline $\begin{array}{l}\text { Ansorge \& Heumann } \\
\quad(2003 \text {, Exp. 3) }\end{array}$ & S-onset & $\begin{array}{l}\text { S-onset of red or green circle } \\
\text { (color blocked) }\end{array}$ & $\begin{array}{l}\text { S-onset (similar color } \\
\text { to target) }\end{array}$ & $3 \mathrm{SOAs}$ & sig. ${ }^{*}$ \\
\hline $\begin{array}{l}\text { Folk \& Remington } \\
\quad(1996, \text { Exp. 1) }\end{array}$ & S-onset & $\begin{array}{l}\text { S-onset of symbol (central arrow } \\
\text { cued target) }\end{array}$ & S-onset & $100 \%$ invalid onset cue & sig. ${ }^{*}$ \\
\hline $\begin{array}{l}\text { Folk \& Remington } \\
\quad(1996, \text { Exp. 2) }\end{array}$ & S-onset & $\begin{array}{l}\text { S-onset of symbol (participants } \\
\text { knew cue location) }\end{array}$ & S-onset & & sig. ${ }^{*}$ \\
\hline $\begin{array}{l}\text { Folk \& Remington } \\
\quad(1996, \text { Exp. 3) }\end{array}$ & S-onset & $\begin{array}{l}\text { S-onset of symbol (cue appeared } \\
\text { between locations) }\end{array}$ & S-onset & $100 \%$ invalid cue & $-11 \mathrm{msec}^{*}$ \\
\hline $\begin{array}{l}\text { Folk \& Remington } \\
\quad(1998, \text { Exp. 1) }\end{array}$ & S-color & $\begin{array}{l}\text { Onset of symbols with S-color } \\
\text { target }\end{array}$ & $\begin{array}{l}\text { S-color (same as } \\
\text { target) }\end{array}$ & & sig. ${ }^{*}$ \\
\hline $\begin{array}{l}\text { Folk \& Remington } \\
\quad(1998 \text {, Exp. 5) }\end{array}$ & S-color & Onset of 3 white $\&$ S-color symbol & S-color & Compatibility & $50 \mathrm{msec}^{*}$ \\
\hline $\begin{array}{l}\text { Folk \& Remington } \\
\qquad(1999, \text { Exp. 1-3) }\end{array}$ & S-onset & $\begin{array}{l}\text { S-onset of symbol (target feature } \\
\text { blocked) }\end{array}$ & S-onset & & sig. ${ }^{*}$ \\
\hline $\begin{array}{l}\text { Folk et al. } \\
\qquad(1992, \text { Exp. 1) }\end{array}$ & S-onset & $\begin{array}{l}\text { S-onset of symbol (target feature } \\
\text { blocked) }\end{array}$ & S-onset & $100 \%$ invalid cue & $-26 \mathrm{msec}^{*}$ \\
\hline $\begin{array}{l}\text { Folk et al. } \\
\qquad(1992, \text { Exp. 2) }\end{array}$ & S-color & Onset of 3 white $\&$ S-color symbol & S-color & $100 \%$ invalid cue & $-42 \mathrm{msec}^{*}$ \\
\hline $\begin{array}{l}\text { Folk et al. } \\
\qquad(1992, \text { Exp. 3) }\end{array}$ & $\begin{array}{l}\text { S-color } \\
\text { S-onset }\end{array}$ & $\begin{array}{l}\text { Onset of } 3 \text { white \& S-color symbol } \\
\text { S-onset of symbol (target feature } \\
\text { random) }\end{array}$ & $\begin{array}{l}\text { S-color } \\
\text { S-onset }\end{array}$ & & $\begin{array}{l}56 \mathrm{msec}^{*} \\
22 \mathrm{msec}^{*}\end{array}$ \\
\hline $\begin{array}{l}\text { Folk et al. } \\
\qquad(1994, \text { Exp. 1) }\end{array}$ & $\begin{array}{l}\text { S-rotation } \\
\text { S-motion }\end{array}$ & $\begin{array}{l}\text { Onset of symbols } \\
\text { Onset of symbols }\end{array}$ & $\begin{array}{l}\text { S-rotating item } \\
\text { S-rotating item (slow) }\end{array}$ & $\begin{array}{l}100 \% \text { invalid cue } \\
100 \% \text { invalid cue }\end{array}$ & $\begin{array}{l}-42 \mathrm{msec}^{*} \\
-54 \mathrm{msec}^{*}\end{array}$ \\
\hline $\begin{array}{l}\text { Folk et al. } \\
\qquad(1994, \text { Exp. 2) }\end{array}$ & S-motion & Onset of symbols & S-rotating item (fast) & $100 \%$ invalid cue & $-54 \mathrm{msec}^{*}$ \\
\hline $\begin{array}{l}\text { Folk et al. } \\
\text { (1994, Exp. 3) }\end{array}$ & S-motion & Onset of symbols & S-rotating item (fast) & & 43 msec $^{*}$ \\
\hline $\begin{array}{l}\text { Folk et al. } \\
\qquad(1994, \text { Exp. 4) }\end{array}$ & $\begin{array}{l}\text { S-motion } \\
\text { S-onset }\end{array}$ & $\begin{array}{l}\text { Onset of symbols } \\
\text { S-onset of symbol }\end{array}$ & $\begin{array}{l}\text { S-rotating item (fast) } \\
\text { S-onset }\end{array}$ & & $\begin{array}{l}45 \mathrm{msec}^{*} \\
25 \mathrm{msec}^{*}\end{array}$ \\
\hline $\begin{array}{l}\text { Gibson \& Amelio } \\
\quad(2000, \text { Exp. 1) }\end{array}$ & $\begin{array}{l}\text { S-onset } \\
\text { S-color }\end{array}$ & $\begin{array}{l}\text { S-onset of letter } \\
\text { Onset of } 3 \text { white \& S-color letter } \\
\text { (target type manipulated between } \\
\text { participants) }\end{array}$ & $\begin{array}{l}\text { S-onset } \\
\text { S-color }\end{array}$ & & $\begin{array}{l}30 \mathrm{msec}^{*} \\
30 \mathrm{msec}^{*}\end{array}$ \\
\hline $\begin{array}{l}\text { Gibson \& Amelio } \\
\quad(2000, \text { Exp. 2) }\end{array}$ & S-onset & S-onset of letter & S-onset & & $21 \mathrm{msec}^{*}$ \\
\hline $\begin{array}{l}\text { Lamy et al. } \\
\qquad(2004, \text { Exp. 1) }\end{array}$ & $\begin{array}{l}\text { Red or green } \\
\text { Item }\end{array}$ & $\begin{array}{l}\text { Color change from gray to colored } \\
\text { placeholders (cue conditions } \\
\text { blocked) }\end{array}$ & $\begin{array}{l}\text { S-color (same color as } \\
\text { target) } \\
\text { Nonsingleton }\end{array}$ & & $\begin{array}{l}55 \mathrm{msec}^{*} \\
52 \mathrm{msec}^{*}\end{array}$ \\
\hline $\begin{array}{l}\text { Lamy et al. } \\
\qquad(2004, \text { Exp. 2) }\end{array}$ & $\begin{array}{l}\text { Red or green } \\
\text { Item }\end{array}$ & $\begin{array}{l}\text { Color change from gray to colored } \\
\text { placeholders (cue conditions } \\
\text { randomized) }\end{array}$ & $\begin{array}{l}\text { S-color (same color as } \\
\text { target) } \\
\text { Nonsingleton (same } \\
\text { color as target) }\end{array}$ & & $\begin{array}{l}40 \mathrm{msec}^{*} \\
40 \mathrm{msec}^{*}\end{array}$ \\
\hline $\begin{array}{l}\text { Pratt et al. } \\
\qquad(2001, \text { Exp. 1) }\end{array}$ & $\begin{array}{l}\text { S-onset } \\
\text { S-color }\end{array}$ & $\begin{array}{l}\text { S-onset of symbol } \\
\text { Onset of symbols with S-color tar- } \\
\text { get (cue-target combinations were } \\
\text { randomized, or target was blocked) }\end{array}$ & $\begin{array}{l}\text { S-onset } \\
\text { S-color }\end{array}$ & $\begin{array}{l}\text { Random } \\
\text { Blocked }\end{array}$ & $\begin{array}{l}34 \mathrm{msec}^{*} \\
67 \mathrm{msec}^{*} \\
101 \mathrm{msec}^{*}\end{array}$ \\
\hline $\begin{array}{l}\text { Rauschenberger } \\
\qquad(2003 \text { b, Exp. 1) }\end{array}$ & S-onset & $\begin{array}{l}\text { Offset of segments \& onset of } \\
\text { target }\end{array}$ & $\begin{array}{l}\text { S-onset (varied } \\
\text { luminance) }\end{array}$ & & $35 \mathrm{msec}^{*}$ \\
\hline $\begin{array}{l}\text { Rauschenberger } \\
\qquad(2003 \text { b, Exp. 2) }\end{array}$ & $\begin{array}{l}\text { S-luminance } \\
\text { transient }\end{array}$ & $\begin{array}{l}\text { Offset of segments \& target lumi- } \\
\text { nance increase }\end{array}$ & S-luminance transient & & $41 \mathrm{msec}^{*}$ \\
\hline $\begin{array}{l}\text { Rauschenberger } \\
\qquad(2003 \text { b, Exp. 3) }\end{array}$ & S-luminance & $\begin{array}{l}\text { Offset of segments \& target lumi- } \\
\text { nance increase }\end{array}$ & $\begin{array}{l}\text { S-luminance transient } \\
\text { (varied contrasts) }\end{array}$ & $\begin{array}{l}12.1: 1 \text { contrast } \\
3.6: 1 \text { contrast } \\
2.5: 1 \text { contrast }\end{array}$ & $\begin{array}{l}28 \mathrm{msec}^{*} \\
25 \mathrm{msec}^{*} \\
25 \mathrm{msec}^{*}\end{array}$ \\
\hline $\begin{array}{l}\text { Remington et al. } \\
\qquad(2001, \text { Exp. } 1)\end{array}$ & S-color & $\begin{array}{l}\text { Onset of } 3 \text { white letters \& S-color } \\
\text { letter (cue was [in]compatible with } \\
\text { response) }\end{array}$ & S-color & $\begin{array}{l}\text { Cuing } \\
\text { Compatibility }\end{array}$ & $\begin{array}{l}\text { sig.*} \\
\text { sig.* }\end{array}$ \\
\hline
\end{tabular}




\begin{tabular}{|c|c|c|c|c|c|}
\hline \multicolumn{6}{|c|}{ APPENDIX (Continued) } \\
\hline Experiment & Target & Target Display Features & Cue Feature & Miscellaneous & Effect \\
\hline $\begin{array}{l}\text { Remington et al. } \\
\text { (2001, Exp. } 2)\end{array}$ & S-color & $\begin{array}{l}\text { Onset of } 3 \text { white letters \& S-color } \\
\text { letter (nontargets were } \\
\text { [in]compatible with response) }\end{array}$ & S-color & $\begin{array}{l}\text { Cuing } \\
\text { Compatibility }\end{array}$ & $\begin{array}{l}\text { sig.* } \\
\text { sig.* }\end{array}$ \\
\hline $\begin{array}{l}\text { Remington et al. } \\
\text { (1992, Exp. 1-3) }\end{array}$ & S-onset & $\begin{array}{l}\text { S-onset of symbol in each of } \\
\text { Experiments } 1-3\end{array}$ & S-onset & Average of Exps. 1-3 & $33 \mathrm{msec}^{*}$ \\
\hline $\begin{array}{l}\text { Richard et al. } \\
\text { (2003, Exp. 4) }\end{array}$ & S-onset & S-onset of tilted line & $\begin{array}{l}\text { Onset of } 3 \text { gray \& } \\
1 \text { red cue }\end{array}$ & & $16 \mathrm{msec}^{*}$ \\
\hline $\begin{array}{l}\text { Snowden } \\
(2002)\end{array}$ & S-onset & Onset of tilted line & S-onset & & sig. ${ }^{*}$ \\
\hline $\begin{array}{l}\text { Snowden et al. } \\
\quad(2001 \text {, Exp. 1) }\end{array}$ & S-onset & $\begin{array}{l}\text { S-onset of line of high or low } \\
\text { contrast with background }\end{array}$ & S-onset & $\begin{array}{l}\text { High contrast } \\
\text { Low contrast }\end{array}$ & $\begin{array}{l}58 \mathrm{msec}^{*} \\
157 \mathrm{msec}^{*}\end{array}$ \\
\hline $\begin{array}{l}\text { Snowden et al. } \\
\quad(2001, \text { Exp. 2) }\end{array}$ & S-onset & $\begin{array}{l}\text { S-onset of line with a hard or easy } \\
\text { orientation to discriminate }\end{array}$ & S-onset & $\begin{array}{l}\text { Hard discrimination } \\
\text { Easy discrimination }\end{array}$ & $\begin{array}{l}54 \mathrm{msec}^{*} \\
74 \mathrm{msec}^{*}\end{array}$ \\
\hline $\begin{array}{l}\text { Wright \& Richard } \\
\text { (2003, Exp. 1) }\end{array}$ & S-onset & S-onset of tilted line & Onset of 1-4 gray cues & $\begin{array}{l}1 \text { cue } \\
2-4 \text { cues (average) }\end{array}$ & $\begin{array}{l}35 \mathrm{msec}^{*} \\
19 \mathrm{msec}^{*}\end{array}$ \\
\hline $\begin{array}{l}\text { Wright \& Richard } \\
\text { (2003, Exp. 2) }\end{array}$ & S-onset & S-onset of tilted line & Onset of 4 gray cues & $\begin{array}{l}\text { SOA } 100 \mathrm{msec} \\
\text { SOA } 200-300 \mathrm{msec}\end{array}$ & $\begin{array}{l}15 \mathrm{msec}^{*} \\
\text { n.s. }\end{array}$ \\
\hline $\begin{array}{l}\text { Wright \& Richard } \\
\text { (2003, Exp. 3) }\end{array}$ & S-onset & $\begin{array}{l}\text { S-onset of tilted line with } 55.5 \mathrm{~cd} / \\
\mathrm{m}^{2} \text { on a black background }\end{array}$ & $\begin{array}{l}\text { Onset of } 4 \text { cues, each } \\
\text { with different } \\
\text { luminance }\end{array}$ & $\begin{array}{l}0.80 \mathrm{~cd} / \mathrm{m}^{2}-1.52 \mathrm{~cd} / \mathrm{m}^{2} \\
6.29 \mathrm{~cd} / \mathrm{m}^{2} \\
14.40 \mathrm{~cd} / \mathrm{m}^{2}\end{array}$ & $\begin{array}{l}\text { n.s. } \\
12 \mathrm{msec}^{*} \\
20 \mathrm{msec}^{*}\end{array}$ \\
\hline \multicolumn{6}{|c|}{ Irrelevant Singleton Experiments } \\
\hline No irrelevant single & experiments fi & ithin Cell I. & & & \\
\hline \multicolumn{6}{|c|}{ Distractor Interference Experiments } \\
\hline $\begin{array}{l}\text { Theeuwes } \\
\text { (1991a, Exp. 1) }\end{array}$ & $\begin{array}{l}\text { S-color or } \\
\text { S-luminance }\end{array}$ & $\begin{array}{l}\text { Onset of red shapes creating a } \\
\text { color \& luminance change (target } \\
\text { type was between participants) }\end{array}$ & $\begin{array}{l}\text { S-luminance } \\
\text { S-color }\end{array}$ & & $\begin{array}{l}\text { sig.*} \\
\text { sig. }\end{array}$ \\
\hline $\begin{array}{l}\text { Theeuwes } \\
\text { (1991a, Exp. 2) }\end{array}$ & S-shape & $\begin{array}{l}\text { Onset of red shapes creating a } \\
\text { color change }\end{array}$ & S-color & & sig.* \\
\hline $\begin{array}{l}\text { Wu \& Remington } \\
\text { (2003, Exp. 2) }\end{array}$ & $\begin{array}{l}\text { S-color } \\
\text { (green) }\end{array}$ & $\begin{array}{l}\text { Color change from green circles to } \\
1 \text { green, possibly } 1 \text { blue, \& } 4-5 \\
\text { red circles }\end{array}$ & S-color (blue) & & sig. ${ }^{*}$ \\
\hline $\begin{array}{l}\text { Wu \& Remington } \\
\text { (2003, Exp. 3) }\end{array}$ & $\begin{array}{l}\text { S-color } \\
\text { (green) }\end{array}$ & $\begin{array}{l}\text { Color change from blue circles to } \\
1 \text { green, possibly } 1 \text { blue, \& } 4-5 \text { red } \\
\text { circles }\end{array}$ & S-color (blue) & & sig. ${ }^{*}$ \\
\hline $\begin{array}{l}\text { Wu \& Remington } \\
\text { (2003, Exp. 4) }\end{array}$ & $\begin{array}{l}\text { S-color } \\
\text { (green) }\end{array}$ & $\begin{array}{l}\text { Color change from } 3 \text { blue } \& \\
3 \text { green circles to } 1 \text { green, possibly } \\
1 \text { blue, \& } 4-5 \text { red circles }\end{array}$ & S-color (blue) & & sig. ${ }^{*}$ \\
\hline
\end{tabular}

Note-Because the $\mathrm{CIOH}$ predicts attentional capture all of the experiments include a localized target. Under the Effect column, "sig." refers to a significant capture effect that was not reported, numerically, in that study, whereas "n.s." refers to a nonsignificant effect. "S" refers to singleton. " $p<$ .05 (two-tailed).

Table A2

Experiments (With a Nonlocalized Target) in Which the DCOH Predicts Attentional Capture, but the CIOH Does Not

\begin{tabular}{|c|c|c|c|}
\hline Experiment & Target Display Features & Miscellaneous & Effect \\
\hline \multicolumn{4}{|c|}{ Spatial Precuing Experiments } \\
\hline $\begin{array}{l}\text { Atchley et al. } \\
\qquad(2000, \text { Exp. } 1)\end{array}$ & $\begin{array}{l}\text { Onset of letters or offset of segments form- } \\
\text { ing letters (target display type blocked) }\end{array}$ & $\begin{array}{l}\text { S-onset } \\
\text { S-offset }\end{array}$ & $\begin{array}{l}23 \mathrm{msec}^{*} \\
36 \text { msec }^{*}\end{array}$ \\
\hline $\begin{array}{l}\text { Atchley et al. } \\
\qquad(2000, \text { Exp. } 1)\end{array}$ & $\begin{array}{l}\text { Onset of letters or offset of segments creat- } \\
\text { ing letters (target display type blocked) }\end{array}$ & $\begin{array}{l}\text { S-offset } \\
\text { S-onset }\end{array}$ & $\begin{array}{l}-3 \mathrm{msec} \\
-4 \mathrm{msec}\end{array}$ \\
\hline $\begin{array}{l}\text { Atchley et al. } \\
\qquad(2000 \text {, Exp. 2) }\end{array}$ & $\begin{array}{l}\text { Onset of letters or offset of segments form- } \\
\text { ing letters (target display type randomized) }\end{array}$ & $\begin{array}{l}\text { S-onset } \\
\text { S-offset }\end{array}$ & $\begin{array}{l}30 \mathrm{msec}^{*} \\
45 \mathrm{msec}^{*}\end{array}$ \\
\hline $\begin{array}{l}\text { Atchley et al. } \\
\qquad(2000, \text { Exp. 2) }\end{array}$ & $\begin{array}{l}\text { Onset of letters or offset of segments creat- } \\
\text { ing letters (target display type randomized) }\end{array}$ & $\begin{array}{l}\text { S-offset } \\
\text { S-onset }\end{array}$ & $\begin{array}{l}\text { n.s. } \\
\text { n.s. }\end{array}$ \\
\hline $\begin{array}{l}\text { Atchley et al. } \\
\qquad(2000, \text { Exp. 3) }\end{array}$ & Offset of segments \& onset of letters & S-offset or S-onset & $20 \mathrm{msec}^{*}$ \\
\hline $\begin{array}{l}\text { Atchley et al. } \\
\qquad(2000, \text { Exp. 4B) }\end{array}$ & $\begin{array}{l}\text { Luminance change on segments to illuminate } \\
\text { letters (larger luminance change than Exp. 4A) }\end{array}$ & S-luminance transient & $25 \mathrm{msec}^{*}$ \\
\hline $\begin{array}{l}\text { Chastain \& Cheal } \\
\text { (2001, Exp. 1A) }\end{array}$ & $\begin{array}{l}\text { Onset of symbols or offset of segments (tar- } \\
\text { get display type blocked) }\end{array}$ & S-onset or S-offset & sig. ${ }^{*}$ \\
\hline $\begin{array}{l}\text { Chastain \& Cheal } \\
\text { (2001, Exp. 1B) }\end{array}$ & $\begin{array}{l}\text { Onset of symbols or offset of segments (tar- } \\
\text { get display type was randomized) }\end{array}$ & S-onset or S-offset & sig. ${ }^{*}$ \\
\hline
\end{tabular}




\begin{tabular}{|c|c|c|c|c|}
\hline \multicolumn{5}{|c|}{ APPENDIX (Continued) } \\
\hline Experiment & Target Display Features & Cue Feature & Miscellaneous & Effect \\
\hline $\begin{array}{l}\text { Chastain \& Cheal } \\
\text { (2001, Exp. 3) }\end{array}$ & Onset of letters & S-luminance transient & & sig.* \\
\hline $\begin{array}{l}\text { Chastain et al. } \\
\text { (2002, Exp. 3) }\end{array}$ & Onset of letters & S-moving item & $100 \%$ invalid cue & $-.05 \mathrm{msec}^{*}$ \\
\hline $\begin{array}{r}\text { Gibson \& Kelsey } \\
(1998, \text { Exp. 1) }\end{array}$ & Onset of red letters & $\begin{array}{l}\text { S-onset } \\
\text { S-color }\end{array}$ & & $\begin{array}{l}44 \mathrm{msec}^{*} \\
47 \mathrm{msec}^{*}\end{array}$ \\
\hline $\begin{array}{r}\text { Gibson \& Kelsey } \\
(1998 \text {, Exp. 2) }\end{array}$ & Onset of white letters & S-onset & & $47 \mathrm{msec}^{*}$ \\
\hline $\begin{array}{l}\text { Johnson et al. } \\
\quad(2001 \text {, Exp. 1) }\end{array}$ & $\begin{array}{l}\text { Onset of colored letters creating a color } \\
\text { change (color of target display \& cue } \\
\text { randomized) }\end{array}$ & $\begin{array}{l}\text { S-color (same/different } \\
\text { color as target display) }\end{array}$ & $\begin{array}{l}\text { Same } \\
\text { Different }\end{array}$ & $\begin{array}{l}9 \mathrm{msec}^{*} \\
12 \mathrm{msec}^{*}\end{array}$ \\
\hline $\begin{array}{l}\text { Johnson et al. } \\
\text { (2001, Exp. 2) }\end{array}$ & $\begin{array}{l}\text { Onset of colored letters creating a color } \\
\text { change (color of target display blocked) }\end{array}$ & $\begin{array}{l}\text { S-color (same/different } \\
\text { color as target display) }\end{array}$ & $\begin{array}{l}\text { Same } \\
\text { Different }\end{array}$ & $\begin{array}{l}9 \mathrm{msec}^{*} \\
19 \mathrm{msec}^{*}\end{array}$ \\
\hline $\begin{array}{l}\text { Johnson et al. } \\
\text { (2001, Exp. 3) } \\
\text { Johnson et al. } \\
\quad(2001 \text {, Exp. 4) }\end{array}$ & $\begin{array}{l}\text { Onset of colored letters creating a color } \\
\text { change (color of target display \& cue blocked) } \\
\text { Onset of colored letters creating a color change } \\
\text { (color of target display \& cue randomized) }\end{array}$ & $\begin{array}{l}\text { S-color (same/different } \\
\text { color as target display) } \\
\text { S-color (same/different } \\
\text { color as target display) }\end{array}$ & $\begin{array}{l}\text { Same } \\
\text { Different } \\
\text { Same } \\
\text { Different }\end{array}$ & $\begin{array}{l}5 \mathrm{msec}^{*} \\
14 \mathrm{msec}^{*} \\
27 \mathrm{msec}^{*} \\
34 \mathrm{msec}^{*}\end{array}$ \\
\hline $\begin{array}{l}\text { Jonides } \\
\quad(1981 \text {, Exp. 2) }\end{array}$ & Onset of letters (instructions: 'attend to cue') & S-onset & & $95 \mathrm{msec}^{*}$ \\
\hline $\begin{array}{l}\text { Juola et al. } \\
\quad(1995, \text { Exp. 1) }\end{array}$ & $\begin{array}{l}\text { Offset \& onset of line segments to form } \\
\text { letters }\end{array}$ & S-onset & $\begin{array}{l}\text { Central arrow } \\
\text { presented }\end{array}$ & $40 \mathrm{msec}^{*}$ \\
\hline $\begin{array}{l}\text { Juola et al. } \\
\quad(1995 \text {, Exp. 2) }\end{array}$ & $\begin{array}{l}\text { Offset \& onset of line segments to form } \\
\text { letters }\end{array}$ & S-onset & $\begin{array}{l}\text { Peripheral arrow } \\
\text { presented }\end{array}$ & $62 \mathrm{msec}^{*}$ \\
\hline $\begin{array}{l}\text { Lamy \& Egeth } \\
\qquad(2003 \text {, Exp. 3) }\end{array}$ & Onset of symbols inside colored circles & S-onset (diamond) & & $21 \mathrm{msec}^{*}$ \\
\hline $\begin{array}{l}\text { Lamy \& Egeth } \\
\qquad(2003 \text {, Exp. 4) }\end{array}$ & Onset of symbols inside colored circles & S-onset (4 dots) & & $20 \mathrm{msec}^{*}$ \\
\hline $\begin{array}{l}\text { Theeuwes } \\
\text { (1991a, Exp. 1) }\end{array}$ & Offset of segments; central arrow cued target & S-onset & & sig. ${ }^{*}$ \\
\hline $\begin{array}{l}\text { Theeuwes } \\
\text { (1991a, Exp. 2) }\end{array}$ & Offset of segments; central arrow cued target & S-offset & & sig. ${ }^{*}$ \\
\hline $\begin{array}{l}\text { Yantis \& Jonides } \\
\quad(1996, \text { Exp. 3) }\end{array}$ & Offset of segments & S-onset & & sig.* \\
\hline \multicolumn{5}{|c|}{ Irrelevant Singleton Experiments } \\
\hline $\begin{array}{l}\text { Abrams \& Christ } \\
(2003 \text {, Exp. 1) }\end{array}$ & $\begin{array}{l}\text { Offset of segments to form letters (set } \\
\text { size }=4 \text { ) }\end{array}$ & S-motion onset & & sig. ${ }^{*}$ \\
\hline $\begin{array}{l}\text { Abrams \& Christ } \\
\quad(2003, \text { Exp. 2) }\end{array}$ & $\begin{array}{l}\text { Offset of segments to form letters (set } \\
\text { size }=3 / 6)\end{array}$ & S-motion onset & & $5.4 \mathrm{msec} /$ item $^{*}$ \\
\hline $\begin{array}{l}\text { Enns et al. } \\
\text { (2001, Exp. 1A) }\end{array}$ & $\begin{array}{l}\text { Offset of segments to form letters (black \& } \\
\text { white letters in displays) }\end{array}$ & S-onset & & 5 vs. $22 \mathrm{msec} /$ item* \\
\hline $\begin{array}{l}\text { Enns et al. } \\
\text { (2001, Exp. 1B) }\end{array}$ & $\begin{array}{l}\text { Offset of segments to form letters (black or } \\
\text { white letters in displays) }\end{array}$ & S-onset & & 9 vs. $23 \mathrm{msec} /$ item* $^{*}$ \\
\hline $\begin{array}{l}\text { Enns et al. } \\
\quad(2001, \text { Exp. 2) }\end{array}$ & & $\begin{array}{l}\text { Offset of segments to } \\
\text { form letters with S-onset } \\
\& \text { S-luminance-change }\end{array}$ & S-onset & 16 vs. $29 \mathrm{msec} /$ item $^{*}$ \\
\hline $\begin{array}{l}\text { Enns et al. } \\
\text { (2001, Exp. 4A) }\end{array}$ & Offset of segments to form letters & $\begin{array}{l}\text { S-onset (high or low } \\
\text { contrast) }\end{array}$ & $\begin{array}{l}\text { High contrast } \\
\text { Low contrast }\end{array}$ & $\begin{array}{l}13.0 \mathrm{msec} / \text { item } \\
17.0 \mathrm{msec} / \mathrm{item}\end{array}$ \\
\hline $\begin{array}{l}\text { Enns et al. } \\
\quad(2001 \text {, Exp. 4B) }\end{array}$ & $\begin{array}{l}\text { Offset of segments to form letters (new con- } \\
\text { trasts used) }\end{array}$ & $\begin{array}{l}\text { S-onset (high or low } \\
\text { contrast) }\end{array}$ & $\begin{array}{l}\text { High contrast } \\
\text { Low contrast }\end{array}$ & $\begin{array}{l}15.0 \mathrm{msec} / \text { item } \\
12.0 \mathrm{msec} / \text { item }\end{array}$ \\
\hline $\begin{array}{l}\text { Franconeri \& Simons } \\
\quad(2003 \text {, Exp. 1) }\end{array}$ & Offset of segments to form letters & S-onset & & 19 vs. $33 \mathrm{msec} /$ item $^{*}$ \\
\hline $\begin{array}{l}\text { Franconeri \& Simons } \\
\quad(2003 \text {, Exp. 2A) }\end{array}$ & & $\begin{array}{l}\text { Offset of segments to } \\
\text { form letters }\end{array}$ & $\begin{array}{l}\text { S-moving item } \\
\text { (behind occluder) }\end{array}$ & 14 vs. $42 \mathrm{msec} /$ item $^{*}$ \\
\hline $\begin{array}{l}\text { Franconeri \& Simons } \\
\quad(2003, \text { Exp. 2B) }\end{array}$ & & $\begin{array}{l}\text { Offset of segments to } \\
\text { form letters }\end{array}$ & $\begin{array}{l}\text { S-moving item (in } \\
\text { front of occluder) }\end{array}$ & 15 vs. $47 \mathrm{msec} /$ item* $^{*}$ \\
\hline $\begin{array}{l}\text { Franconeri \& Simons } \\
\quad(2003 \text {, Exp. 2C) }\end{array}$ & Offset of segments to form letters & $\begin{array}{l}\text { S-moving item (no } \\
\text { occluder) }\end{array}$ & & 17 vs. $42 \mathrm{msec} /$ item* $^{*}$ \\
\hline $\begin{array}{l}\text { Franconeri \& Simons } \\
\quad(2003 \text {, Exp. 2D) }\end{array}$ & & $\begin{array}{l}\text { Offset of segments to } \\
\text { form letters }\end{array}$ & S-jittering item & 14 vs. $31 \mathrm{msec} /$ item $^{*}$ \\
\hline $\begin{array}{l}\text { Franconeri \& Simons } \\
\quad(2003 \text {, Exp. 3) }\end{array}$ & Offset of segments to form letters & S-increasing size & & 17 vs. $43 \mathrm{msec} /$ item $^{*}$ \\
\hline $\begin{array}{l}\text { Gibson } \\
\quad(1996, \text { Exp. 2) }\end{array}$ & $\begin{array}{l}\text { Offset of segments to form letters (bright } \\
\text { stimuli) }\end{array}$ & S-onset & & 7.7 vs. $30.7 \mathrm{msec} /$ item$^{*}$ \\
\hline
\end{tabular}




\begin{tabular}{|c|c|c|c|c|}
\hline \multicolumn{5}{|c|}{ APPENDIX (Continued) } \\
\hline Experiment & Target Display Features & Cue Feature & Miscellaneous & Effect \\
\hline $\begin{array}{l}\text { Hillstrom \& Yantis } \\
\text { (1994, Exp. 2) }\end{array}$ & $\begin{array}{l}\text { Offset of segments to form letters, which } \\
\text { formed target's shape (cue compatibility } \\
\text { manipulated) }\end{array}$ & S-motion or S-onset & & sig.* \\
\hline $\begin{array}{l}\text { Hillstrom \& Yantis } \\
\text { (1994, Exp. 3) }\end{array}$ & $\begin{array}{l}\text { Offset of segments to form letters, which } \\
\text { formed target's shape (cue compatibility } \\
\text { manipulated) }\end{array}$ & $\begin{array}{l}\text { S-motion (late } \\
\text { movement) }\end{array}$ & & sig. ${ }^{*}$ \\
\hline $\begin{array}{l}\text { Jonides \& Yantis } \\
\quad(1988, \text { Exp. 1) }\end{array}$ & $\begin{array}{l}\text { Offset of segments to form letters (set sizes } \\
2-4 \text { ) }\end{array}$ & S-onset & & $0.5 \mathrm{msec} /$ item $^{+}$ \\
\hline $\begin{array}{l}\text { Jonides \& Yantis } \\
\quad(1988 \text {, Exp. 2) }\end{array}$ & $\begin{array}{l}\text { Offset of segments to form letters (set sizes } \\
3,5,7)\end{array}$ & S-onset & & $3.6 \mathrm{msec} /$ item $^{+}$ \\
\hline $\begin{array}{l}\text { Martin-Emerson \& } \\
\text { Kramer (1997, } \\
\text { Exp. 1) }\end{array}$ & Offset of segments to form letters & S-onset & $\begin{array}{l}\text { Set size } 3-5 \\
\text { Set size } 5-13\end{array}$ & $\begin{array}{l}\text { sig.* } \\
\text { n.s. }\end{array}$ \\
\hline $\begin{array}{l}\text { Miller } \\
\quad(1989, \text { Exp. 1) }\end{array}$ & $\begin{array}{l}\text { Offset of segments to form letters (\# offset } \\
\text { segments equal to \# onset segments) }\end{array}$ & S-onset & & 26 vs. 45 msec/item* \\
\hline $\begin{array}{l}\text { Miller } \\
\quad(1989, \text { Exp. 2) }\end{array}$ & Offset of segments to form letters & S-onset & & 9 vs. 46 msec/item* \\
\hline $\begin{array}{l}\text { Peterson \& Kramer } \\
\quad(2001 \text {, Exp. 1) }\end{array}$ & Offset of segments to form letters & S-onset & & sig.* \\
\hline $\begin{array}{l}\text { Peterson \& Kramer } \\
\text { (2001, Exp. 3) }\end{array}$ & Offset of segments to form letters & S-onset & & sig.* \\
\hline $\begin{array}{l}\text { Theeuwes } \\
\text { (1990, Exp. 3) }\end{array}$ & $\begin{array}{l}\text { Onset of diamonds with onset of cue } \\
260 \text { msec later }\end{array}$ & S-onset & & 36.3 vs. $81.5 \mathrm{msec}$ item $^{*}$ \\
\hline $\begin{array}{l}\text { Turatto \& Galfano } \\
\quad(2000, \text { Exp. 1) }\end{array}$ & $\begin{array}{l}\text { Onset of colored discs that created a color } \\
\text { change }\end{array}$ & S-color & & sig.* \\
\hline $\begin{array}{l}\text { Turatto \& Galfano } \\
\quad(2000, \text { Exp. 2) }\end{array}$ & $\begin{array}{l}\text { Onset of discs and a diamond that created a } \\
\text { shape change ('Shape' was relevant) }\end{array}$ & S-shape & & sig.* \\
\hline $\begin{array}{l}\text { Turatto \& Galfano } \\
\text { (2000, Exp. 3) }\end{array}$ & $\begin{array}{l}\text { Onset of gray discs that created a luminance } \\
\text { change }\end{array}$ & S-luminance & & sig. ${ }^{*}$ \\
\hline $\begin{array}{l}\text { Turatto \& Galfano } \\
\text { (2001, Exp. 1) }\end{array}$ & $\begin{array}{l}\text { Onset of colored discs creating a color } \\
\text { change }\end{array}$ & S-color & & sig. ${ }^{*}$ \\
\hline $\begin{array}{l}\text { Turatto \& Galfano } \\
\text { (2001, Exp. 2A) }\end{array}$ & $\begin{array}{l}\text { Onset of colored discs creating a color } \\
\text { change }\end{array}$ & S-color & & sig. ${ }^{*}$ \\
\hline $\begin{array}{l}\text { Turatto et al. }(2004 \text {, } \\
\text { Exp. } 1,3,4)\end{array}$ & $\begin{array}{l}\text { Onset of colored discs that created a color } \\
\text { change }\end{array}$ & S-color & & sig.* \\
\hline $\begin{array}{l}\text { Yantis \& Egeth } \\
\text { (1999, Exp. 3) }\end{array}$ & $\begin{array}{l}\text { Onset of colored bars that created a color } \\
\text { change }\end{array}$ & S-color & & 39.7 vs. $53.3 \mathrm{msec} /$ item $^{*}$ \\
\hline $\begin{array}{l}\text { Yantis \& Egeth } \\
\quad(1999, \text { Exp. 6) }\end{array}$ & $\begin{array}{l}\text { Onset of colored bars that created a color } \\
\text { change }\end{array}$ & S-color & & sig. ${ }^{*}$ \\
\hline $\begin{array}{l}\text { Yantis \& Johnson } \\
\quad(1990 \text {, Exp. 1-3) }\end{array}$ & Offset of segments to form letters with & Onset of new items & & sig. ${ }^{*}$ \\
\hline $\begin{array}{l}\text { Yantis \& Jonides } \\
\quad(1984, \text { Exp. 1) }\end{array}$ & Offset of segments to form letters & S-onset & & $7.9 \mathrm{msec} /$ item $^{+}$ \\
\hline $\begin{array}{r}\text { Yantis \& Jonides } \\
\quad(1984, \text { Exp. 3) }\end{array}$ & $\begin{array}{l}\text { Gradual or abrupt offset of segments to form } \\
\text { letters }\end{array}$ & S-onset & $\begin{array}{l}\text { Gradual offset } \\
\text { Abrupt offset }\end{array}$ & $\begin{array}{l}9.0 \mathrm{msec} / \text { item }^{+} \\
7.0 \mathrm{msec} / \text { item }^{+}\end{array}$ \\
\hline $\begin{array}{r}\text { Yantis \& Jonides } \\
\quad(1990, \text { Exp. 1) }\end{array}$ & $\begin{array}{l}\text { Offset of segments \& onset of letter; central } \\
\text { arrow cued target on } 80 \% \text { of trials }\end{array}$ & S-onset & $\begin{array}{l}\text { Invalid arrow } \\
\text { Valid arrow }\end{array}$ & $\begin{array}{l}25 \mathrm{msec}^{*} \\
8 \mathrm{msec}\end{array}$ \\
\hline $\begin{array}{r}\text { Yantis \& Jonides } \\
\quad(1990 \text {, Exp. 2) }\end{array}$ & $\begin{array}{l}\text { Offset of segments \& onset of letter; central } \\
\text { arrow cued target on all trials; arrow-target } \\
\text { SOA varied }\end{array}$ & S-onset & $\begin{array}{r}-200 \mathrm{msec} \text { SOA } \\
0 \mathrm{msec} \text { SOA } \\
+200 \mathrm{msec} \text { SOA }\end{array}$ & $\begin{array}{r}8 \mathrm{msec} \\
52 \mathrm{msec}^{*} \\
117 \mathrm{msec}^{*}\end{array}$ \\
\hline $\begin{array}{l}\text { Yantis \& Jonides } \\
\quad(1990, \text { Exp. 3A) }\end{array}$ & $\begin{array}{l}\text { Offset of segments \& onset of letter; central } \\
\text { arrow cued target on } 75 \% \text { of trials }\end{array}$ & S-onset & $\begin{array}{l}\text { Invalid arrow } \\
\text { Valid arrow }\end{array}$ & $\begin{aligned} 121 \mathrm{msec}^{*} \\
48 \mathrm{msec}^{*}\end{aligned}$ \\
\hline $\begin{array}{l}\text { Yantis \& Jonides } \\
\quad(1990, \text { Exp. 3B) }\end{array}$ & $\begin{array}{l}\text { Offset of segments \& onset of letter; central } \\
\text { arrow cued target on } 25 \% \text { of trials }\end{array}$ & S-onset & $\begin{array}{l}\text { Invalid arrow } \\
\text { Valid arrow }\end{array}$ & $\begin{array}{l}69 \mathrm{msec}^{*} \\
46 \mathrm{msec}^{*}\end{array}$ \\
\hline $\begin{array}{l}\text { Yantis \& Jonides } \\
\text { (1996, Exp. 3) }\end{array}$ & Offset of segments to form letters & S-onset & & 2 vs. 13.4 msec/item* \\
\hline \multicolumn{5}{|c|}{ Distractor Interference Experiments } \\
\hline $\begin{array}{l}\text { Peterson \& Kramer } \\
\quad(2001, \text { Exp. 1) }\end{array}$ & Offset of segments creating letters & S-onset & & sig.* \\
\hline $\begin{array}{l}\text { Peterson \& Kramer } \\
\text { (2001, Exp. 2) }\end{array}$ & Offset of segments creating letters & $\begin{array}{l}\text { S-onset (included after } \\
3 / 4 \text { of trials) }\end{array}$ & & sig.* \\
\hline $\begin{array}{l}\text { Theeuwes } \\
\text { (2004, Exp. 1) }\end{array}$ & $\begin{array}{l}\text { Onset of colored shapes creating a color } \\
\text { change }\end{array}$ & S-color & & $-65 \mathrm{msec}^{*}$ \\
\hline
\end{tabular}




\begin{tabular}{|c|c|c|c|c|}
\hline \multicolumn{5}{|c|}{ APPENDIX (Continued) } \\
\hline Experiment & Target Display Features & Cue Feature & Miscellaneous & Effect \\
\hline $\begin{array}{l}\text { Theeuwes \& Burger } \\
\text { (1998, Exp. 1) }\end{array}$ & $\begin{array}{l}\text { Onset of colored letters creating a color } \\
\text { change (target \& distractor colors varied) }\end{array}$ & S-color & & $-50 \mathrm{msec}^{*}$ \\
\hline $\begin{array}{l}\text { Theeuwes \& Burger } \\
\text { (1998, Exp. 3) }\end{array}$ & $\begin{array}{l}\text { Onset of colored letters creating a color } \\
\text { change (target color constant, but distractor } \\
\text { color varied) }\end{array}$ & S-color & & sig.* \\
\hline $\begin{array}{l}\text { Theeuwes \& Burger } \\
\text { (1998, Exp. 4) }\end{array}$ & $\begin{array}{l}\text { Onset of colored letters creating a color } \\
\text { change (target color varied, but distractor } \\
\text { color constant) }\end{array}$ & S-color & & sig.* \\
\hline \multicolumn{5}{|c|}{$\begin{array}{l}\text { Note-There is no Target column because the target in each of these experiments could not be distinguished from the nontargets by any unique fea- } \\
\text { ture. The DCOH makes the correct prediction and the } \mathrm{CIOH} \text { the incorrect prediction for experiments that obtained capture. In contrast, the DCOH } \\
\text { makes the incorrect prediction, and the CIOH the correct prediction, for experiments that did not obtain capture. Under the Effect column, "sig." } \\
\text { refers to a significant capture effect that was not reported, numerically, in that study, whereas "n.s." refers to a nonsignificant effect. For experiments } \\
\text { listed with two RT/Item slopes, the first is the target-singleton condition and the second is the target-nonsingleton condition. When the two slopes } \\
\text { are statistically equivalent the cue did not capture attention. "S" refers to singleton. " } p<.05 \text { (two-tailed). " } p<.05 \text { (one-tailed). " The RT/Item } \\
\text { slope is not different than } 0.0 \mathrm{msec} / \text { item, which suggests that attentional capture was obtained. }\end{array}$} \\
\hline
\end{tabular}

Table A3

Experiments (With a Localized Target) In Which DCOH Predicts Attentional Capture, but the CIOH Does Not

\begin{tabular}{|c|c|c|c|c|c|}
\hline Experiment & Target & Target Display Features & Cue Feature & Miscellaneous & Effect \\
\hline \multicolumn{6}{|c|}{ Spatial Precuing Experiments } \\
\hline $\begin{array}{l}\text { Ansorge \& Heumann } \\
\quad(2003 \text {, Exp. 1) }\end{array}$ & S-onset & S-onset of red or green circle & $\begin{array}{l}\text { S-onset (different } \\
\text { color as target) }\end{array}$ & & $16 \mathrm{msec}^{*}$ \\
\hline $\begin{array}{l}\text { Ansorge \& Heumann } \\
\text { (2003, Exp. 3) }\end{array}$ & S-onset & $\begin{array}{l}\text { S-onset of red/green circle (target } \\
\text { color blocked) }\end{array}$ & $\begin{array}{l}\text { S-onset (different } \\
\text { color as target) }\end{array}$ & & n.s. \\
\hline $\begin{array}{l}\text { Chastain \& Cheal } \\
\text { (1998, Exp. 3) }\end{array}$ & S-symbol & Onset of symbols & S-onset & & sig.* \\
\hline \multirow[t]{2}{*}{$\begin{array}{l}\text { Chastain \& Cheal } \\
\text { (2001, Exp. 2) }\end{array}$} & S-letter & Onset of 3 Os \& 1 rotated C & $\begin{array}{l}\text { S-shape-change } \\
\text { (transient) }\end{array}$ & & $.31^{*}$ \\
\hline & & & S-offset & & $.17^{*}$ \\
\hline $\begin{array}{l}\text { Chastain \& Cheal } \\
\text { (2001, Exp. 3) }\end{array}$ & S-letter & Onset of 3 Os \& 1 rotated C & S-luminance transient & & sig.* \\
\hline $\begin{array}{l}\text { Chastain et al. } \\
\text { (2002, Exp. 1) }\end{array}$ & S-letter & Onset of 3 Xs \& 1 rotated C & S-moving item & & $.19^{*}$ \\
\hline $\begin{array}{l}\text { Chastain et al. } \\
\text { (2002, Exp. 2) }\end{array}$ & S-letter & Onset of 3 Xs \& 1 rotated C & S-moving item & $100 \%$ invalid cue & $-.07^{*}$ \\
\hline $\begin{array}{l}\text { Folk \& Remington } \\
\text { (1998, Exp. 1A) }\end{array}$ & Red/green & $\begin{array}{l}\text { Onset of symbols with } 2 \text { colors } \\
\text { present }\end{array}$ & $\begin{array}{l}\text { S-color (different } \\
\text { from target) }\end{array}$ & & n.s. \\
\hline $\begin{array}{l}\text { Folk \& Remington } \\
\quad(1998, \text { Exp. 1B) }\end{array}$ & S-color & $\begin{array}{l}\text { Onset of symbols with S-color } \\
\text { target }\end{array}$ & $\begin{array}{l}\text { S-color (different } \\
\text { from target) }\end{array}$ & & n.s. \\
\hline $\begin{array}{l}\text { Folk \& Remington } \\
\quad(1999, \text { Exp. 1-3) }\end{array}$ & S-color & $\begin{array}{l}\text { S-onset of symbol (target feature } \\
\text { was blocked) }\end{array}$ & S-onset & & n.s. \\
\hline $\begin{array}{l}\text { Folk \& Remington } \\
\quad(1999, \text { Exp. 4) }\end{array}$ & S-color & S-onset of symbol & S-onset & Compatibility & $1 \mathrm{msec}$ \\
\hline $\begin{array}{l}\text { Folk et al. } \\
\qquad(1992, \text { Exp. 1) }\end{array}$ & S-color & $\begin{array}{l}\text { Onset of symbols (target feature } \\
\text { blocked) }\end{array}$ & S-onset & $100 \%$ invalid cue & $4 \mathrm{msec}$ \\
\hline $\begin{array}{l}\text { Folk et al. } \\
\text { (1992, Exp. 3) }\end{array}$ & S-color & Onset of symbols & S-onset & & $1 \mathrm{msec}$ \\
\hline $\begin{array}{l}\text { Folk et al. } \\
\text { (1994, Exp. 1A) }\end{array}$ & S-onset & S-onset of symbol & S-rotating item (slow) & $100 \%$ invalid cue & $-7 \mathrm{msec}$ \\
\hline $\begin{array}{l}\text { Folk et al. } \\
\text { (1994, Exp. 1B) }\end{array}$ & S-color & $\begin{array}{l}\text { Onset of symbols with S-color } \\
\text { target }\end{array}$ & S-rotating item (slow) & $100 \%$ invalid cue & $-5 \mathrm{msec}$ \\
\hline $\begin{array}{l}\text { Folk et al. } \\
\text { (1994, Exp. 2A) }\end{array}$ & S-onset & S-onset of symbol & S-rotating item (fast) & $100 \%$ invalid cue & n.s. \\
\hline $\begin{array}{l}\text { Folk et al. } \\
\qquad \text { (1994, Exp. 2B) }\end{array}$ & S-color & $\begin{array}{l}\text { Onset of symbols with S-color } \\
\text { target }\end{array}$ & S-rotating item (fast) & $100 \%$ invalid cue & n.s. \\
\hline $\begin{array}{l}\text { Folk et al. } \\
\text { (1994, Exp. 3) }\end{array}$ & S-color & $\begin{array}{l}\text { Onset of symbols with S-color } \\
\text { target }\end{array}$ & S-rotating item (fast) & & $-1 \mathrm{msec}$ \\
\hline $\begin{array}{l}\text { Folk et al. } \\
\text { (1994, Exp. 4A) }\end{array}$ & S-onset & S-onset of symbol & S-rotating item (fast) & & $10 \mathrm{msec}$ \\
\hline $\begin{array}{l}\text { Folk et al. } \\
\text { (1994, Exp. 4B) }\end{array}$ & S-motion & Onset of target symbol & S-onset & & $32 \mathrm{msec}^{*}$ \\
\hline $\begin{array}{l}\text { Gibson \& Amelio } \\
\quad(2000, \text { Exp. 1) }\end{array}$ & S-color & $\begin{array}{l}\text { Onset of letters (target type be- } \\
\text { tween participants) }\end{array}$ & S-onset & & $-9 \mathrm{msec}$ \\
\hline
\end{tabular}




\begin{tabular}{|c|c|c|c|c|c|}
\hline \multicolumn{6}{|c|}{ APPENDIX (Continued) } \\
\hline Experiment & Target & Target Display Features & Cue Feature & Miscellaneous & Effect \\
\hline $\begin{array}{l}\text { Lambert et al. } \\
\text { (1987) }\end{array}$ & S-onset & S-onset of target square & $\begin{array}{l}\text { S-transient color } \\
\text { change }\end{array}$ & & sig. ${ }^{*}$ \\
\hline $\begin{array}{l}\text { Lamy \& Egeth } \\
\quad(2003 \text {, Exp. 2) }\end{array}$ & S-color & Onset of symbols inside circles & S-onset & $\begin{array}{l}\text { Cuing } \\
\text { Interference }\end{array}$ & $\begin{aligned} & 29 \mathrm{msec}^{*} \\
- & 14 \mathrm{msec}^{*}\end{aligned}$ \\
\hline $\begin{array}{l}\text { Lamy \& Egeth } \\
\quad(2003 \text {, Exp. 3) }\end{array}$ & $\begin{array}{l}\text { S-color or } \\
\text { specific color }\end{array}$ & Onset of symbols inside circles & S-onset (diamond) & $\begin{array}{l}\text { S-color target } \\
\text { Specific color target }\end{array}$ & $\begin{array}{l}24 \mathrm{msec}^{*} \\
21 \mathrm{msec}^{*}\end{array}$ \\
\hline $\begin{array}{l}\text { Lamy \& Egeth } \\
\qquad(2003 \text {, Exp. 4) }\end{array}$ & $\begin{array}{l}\text { S-color or } \\
\text { specific color }\end{array}$ & Onset of symbols inside circles & S-onset (4 dots) & $\begin{array}{l}\text { S-color target } \\
\text { Specific color target }\end{array}$ & $\begin{array}{l}22 \mathrm{msec}^{*} \\
20 \mathrm{msec}^{*}\end{array}$ \\
\hline $\begin{array}{l}\text { Lamy et al. } \\
\qquad(2004 \text {, Exp. 1) }\end{array}$ & $\begin{array}{l}\text { Red/green } \\
\text { item }\end{array}$ & $\begin{array}{l}\text { Color change from gray to colored } \\
\text { placeholders (cue conditions } \\
\text { blocked) }\end{array}$ & $\begin{array}{l}\text { S-color (different } \\
\text { color from target) }\end{array}$ & & $-24 \mathrm{msec}^{*}$ \\
\hline $\begin{array}{l}\text { Posner \& Cohen } \\
\quad(1984)\end{array}$ & S-onset & $\begin{array}{l}\text { S-onset of square inside } \\
\text { placeholder }\end{array}$ & S-luminance transient & & sig.* \\
\hline $\begin{array}{l}\text { Pratt \& McAuliffe } \\
\quad(2001 \text {, Exp. 1-2) }\end{array}$ & $\begin{array}{l}\text { S-size } \\
\text { increase }\end{array}$ & S-Increase in size of placeholder & S-onset or S-offset & & sig. ${ }^{*}$ \\
\hline $\begin{array}{l}\text { Pratt \& McAuliffe } \\
\quad(2001 \text {, Exp. 1C) }\end{array}$ & $\begin{array}{l}\text { S-size } \\
\text { increase }\end{array}$ & S-Increase in size of placeholder & $\begin{array}{l}\text { S-onset (with simulta- } \\
\text { neous offset) }\end{array}$ & & sig. ${ }^{*}$ \\
\hline $\begin{array}{l}\text { Pratt et al. } \\
\text { (2001, Exp. 1) }\end{array}$ & S-color & $\begin{array}{l}\text { S-onset of symbol or onset of } 4 \\
\text { items with S-color target (target } \\
\text { type blocked) }\end{array}$ & S-onset & & $4 \mathrm{msec}$ \\
\hline $\begin{array}{l}\text { Rauschenberger } \\
\text { (2003b, Exp. 1) }\end{array}$ & S-onset & $\begin{array}{l}\text { Offset of segments \& onset of } \\
\text { target }\end{array}$ & $\begin{array}{l}\text { S-luminance transient } \\
\text { (varied contrast) }\end{array}$ & $\begin{array}{l}\text { Small-medium contrast } \\
\text { Large contrast }\end{array}$ & $\begin{array}{l}\text { n.s. } \\
\text { sig.* }\end{array}$ \\
\hline $\begin{array}{l}\text { Rauschenberger } \\
\text { (2003b, Exp. 2) }\end{array}$ & $\begin{array}{l}\text { S-luminance } \\
\text { transient }\end{array}$ & $\begin{array}{l}\text { Offset of segments \& target lumi- } \\
\text { nance increase }\end{array}$ & $\begin{array}{l}\text { S-onset (varied } \\
\text { contrast) }\end{array}$ & & sig.* \\
\hline $\begin{array}{l}\text { Rauschenberger } \\
\quad(2003 \text { b, Exp. 3) }\end{array}$ & $\begin{array}{l}\text { S-luminance } \\
\text { transient }\end{array}$ & $\begin{array}{l}\text { Offset of segments \& target lumi- } \\
\text { nance increase }\end{array}$ & $\begin{array}{l}\text { S-onset (varied new } \\
\text { contrasts) }\end{array}$ & $\begin{array}{r}12.1: 1 \\
<3.6: 1\end{array}$ & $\begin{array}{l}27 \mathrm{msec}^{*} \\
\text { n.s. }\end{array}$ \\
\hline
\end{tabular}

Irrelevant Singleton Experiments

No irrelevant singleton experiments fit within Cell IIb.

\begin{tabular}{|c|c|c|c|}
\hline \multirow[b]{2}{*}{$\begin{array}{l}\text { Bacon \& Egeth } \\
\quad \text { (1994, Exp. 1) }\end{array}$} & \multirow[b]{2}{*}{ S-shape } & \multicolumn{2}{|c|}{ Distractor Interference Experiments } \\
\hline & & $\begin{array}{l}\text { Onset of red shapes that created a } \\
\text { color change }\end{array}$ & S-color \\
\hline $\begin{array}{l}\text { Bacon \& Egeth } \\
\quad(1994, \text { Exp. 3) }\end{array}$ & Green-circle & $\begin{array}{l}\text { Onset of red shapes that created a } \\
\text { color change }\end{array}$ & S-color \\
\hline $\begin{array}{l}\text { Irwin et al. } \\
\quad(2000, \text { Exp. 1) }\end{array}$ & S-color & $\begin{array}{l}\text { Offset of segments \& color change } \\
\text { from all gray to } 1 \text { gray \& } 4-5 \text { red } \\
\text { circles }\end{array}$ & S-onset \\
\hline $\begin{array}{l}\text { Irwin et al. } \\
\quad(2000, \text { Exp. 2A) }\end{array}$ & $\begin{array}{l}\text { S-color- } \\
\text { transient }\end{array}$ & $\begin{array}{l}\text { Offset of segments \& S-color tran- } \\
\text { sient target }\end{array}$ & S-onset \\
\hline $\begin{array}{l}\text { Irwin et al. } \\
\quad(2000 \text {, Exp. 2B) }\end{array}$ & S-onset & $\begin{array}{l}\text { Offset of segments \& S-onset } \\
\text { target }\end{array}$ & S-color-transient \\
\hline $\begin{array}{l}\text { Irwin et al. } \\
\quad(2000, \text { Exp. 3A) }\end{array}$ & $\begin{array}{l}\text { S-luminance- } \\
\text { transient }\end{array}$ & $\begin{array}{l}\text { Offset of segments \& } \\
\text { S-luminance-transient }\end{array}$ & S-onset \\
\hline $\begin{array}{l}\text { Irwin et al. } \\
\quad(2000 \text {, Exp. 3B) }\end{array}$ & S-onset & Offset of segments \& S-onset & S-luminance-transient \\
\hline $\begin{array}{l}\text { Lamy et al. } \\
\qquad(2003, \text { Exp. 1) }\end{array}$ & S-shape & $\begin{array}{l}\text { Onset of shapes that created a } \\
\text { color change }\end{array}$ & S-color \\
\hline $\begin{array}{l}\text { Olivers \& Humphreys } \\
\quad \text { (2003) }\end{array}$ & S-size & $\begin{array}{l}\text { Onset of lines that created a color } \\
\text { change }\end{array}$ & S-color \\
\hline $\begin{array}{l}\text { Pashler } \\
\qquad \text { (1988, Exp. 6-7) }\end{array}$ & S-shape & $\begin{array}{l}\text { Onset of shapes that created a } \\
\text { color change }\end{array}$ & S-color \\
\hline $\begin{array}{l}\text { Theeuwes } \\
\text { (1991a, Exp. 3) }\end{array}$ & S-shape & $\begin{array}{l}\text { Onset of red shapes that created a } \\
\text { color change }\end{array}$ & S-color \\
\hline $\begin{array}{l}\text { Theeuwes } \\
\text { (1992, Exp. 1A-B) }\end{array}$ & S-shape & $\begin{array}{l}\text { Onset of red shapes that created a } \\
\text { color change (more trials in } \\
\text { Exp. 1B) }\end{array}$ & S-color \\
\hline $\begin{array}{l}\text { Theeuwes } \\
\text { (1992, Exp. 2) }\end{array}$ & S-shape & $\begin{array}{l}\text { Onset of red shapes that created a } \\
\text { color change }\end{array}$ & $\begin{array}{l}\text { S-color (less salient } \\
\text { than Exp. 1A) }\end{array}$ \\
\hline $\begin{array}{l}\text { Theeuwes } \\
\text { (1994, Exp. 1) }\end{array}$ & S-onset & $\begin{array}{l}\text { Offset of segments; onset of green } \\
\text { circle creating a color change; } \\
\text { color change at distractor location }\end{array}$ & S-color \\
\hline $\begin{array}{l}\text { Theeuwes } \\
\text { (1994, Exp. 1-2) }\end{array}$ & S-color & $\begin{array}{l}\text { Offset of segments \& color change } \\
\text { in display }\end{array}$ & S-onset \\
\hline $\begin{array}{l}\text { Theeuwes } \\
\text { (1994, Exp. 2) }\end{array}$ & S-onset & $\begin{array}{l}\text { Offset of segments; onset of green } \\
\text { circle creating a color change }\end{array}$ & S-color \\
\hline
\end{tabular}

sig.*

$-3 \mathrm{msec}$

$-51 \mathrm{msec}^{*}$

Session 1

Session 2

Session 1

Session 2

Session 2

Exp. 6

Exp. 7

Exp. 1A

Exp. 1B

$-33 \mathrm{msec}^{*}$
$-68 \mathrm{msec}^{*}$
$7 \mathrm{msec}$
$-53 \mathrm{msec}$
$-93 \mathrm{msec}^{*}$
$-51 \mathrm{msec}^{*}$
sig.*
sig.*
$.057 \mathrm{msec}^{*}$
$-47 \mathrm{msec}^{*}$
sig.*
sig.*
sig.*
sig.*
sig.*
sig.*
n.s. 


\begin{tabular}{|c|c|c|c|c|c|}
\hline \multicolumn{6}{|c|}{ APPENDIX (Continued) } \\
\hline Experiment & Target & Target Display Features & Cue Feature & Miscellaneous & Effect \\
\hline $\begin{array}{l}\text { Theeuwes } \\
\text { (1996, Exp. 1) }\end{array}$ & S-shape & $\begin{array}{l}\text { Onset of red shapes that created a } \\
\text { color change (circular display) }\end{array}$ & S-color & $\begin{array}{l}\text { Interference } \\
\text { Compatibility }\end{array}$ & $\begin{array}{l}\text { sig. }{ }^{*} \\
\text { sig. }\end{array}$ \\
\hline $\begin{array}{l}\text { Theeuwes } \\
\text { (1996, Exp. 2) }\end{array}$ & S-shape & $\begin{array}{l}\text { Onset of red shapes that created a } \\
\text { color change (square shaped } \\
\text { display) }\end{array}$ & S-color & $\begin{array}{l}\text { Interference } \\
\text { Compatibility }\end{array}$ & $\begin{array}{r}-28 \mathrm{msec}^{*} \\
38 \mathrm{msec}^{*}\end{array}$ \\
\hline $\begin{array}{l}\text { Theeuwes \& Burger } \\
\text { (1998, Exp. 2) }\end{array}$ & NL & $\begin{array}{l}\text { Onset of colored letters that cre- } \\
\text { ated a color change (colors fixed } \\
\text { across trials) }\end{array}$ & S-color & & n.s. \\
\hline $\begin{array}{l}\text { Theeuwes et al. } \\
\text { (2003, Exp. 1) }\end{array}$ & S-shape & $\begin{array}{l}\text { Onset of green or red shapes creat- } \\
\text { ing a color change }\end{array}$ & S-color & & $-208 \mathrm{msec}^{*}$ \\
\hline $\begin{array}{l}\text { Theeuwes et al. } \\
\text { (2003, Exp. 2) }\end{array}$ & S-shape & $\begin{array}{l}\text { Onset of green shapes that created } \\
\text { a color change }\end{array}$ & S-color & & $-20 \mathrm{msec}^{*}$ \\
\hline $\begin{array}{l}\text { Theeuwes et al. } \\
\text { (1998, Exp. 1) }\end{array}$ & S-color & $\begin{array}{l}\text { Offset of segments creating letters } \\
\& \text { color change }\end{array}$ & S-onset & & $-55 \mathrm{msec}^{*}$ \\
\hline $\begin{array}{l}\text { Theeuwes et al. } \\
\text { (1999, Exp. 1) }\end{array}$ & S-color & $\begin{array}{l}\text { Offset of segments \& color change } \\
\text { of circles }\end{array}$ & S-onset & & sig.* \\
\hline $\begin{array}{l}\text { Theeuwes et al. } \\
\text { (1999, Exp. 2) }\end{array}$ & S-color & $\begin{array}{l}\text { Offset of segments \& color change } \\
\text { of circles }\end{array}$ & S-onset & $\begin{array}{l}\text { Interference } \\
\text { Compatibility }\end{array}$ & $\begin{array}{l}-75 \mathrm{msec}^{*} \\
29 \mathrm{msec}^{*}\end{array}$ \\
\hline $\begin{array}{l}\text { Theeuwes et al. } \\
\text { (2004) }\end{array}$ & S-shape & $\begin{array}{l}\text { Onset of shapes that created a } \\
\text { color change }\end{array}$ & S-color & & sig.* \\
\hline $\begin{array}{l}\text { Wu \& Remington } \\
\text { (2003, Exp. 1) }\end{array}$ & S-color & $\begin{array}{l}\text { Offset of segments \& color change } \\
\text { from all green to } 1 \text { green and } 5 \text { red } \\
\text { circles }\end{array}$ & S-onset & & $-8 \mathrm{msec}^{*}$ \\
\hline $\begin{array}{l}\text { Wu \& Remington } \\
\text { (2003, Exp. 2) }\end{array}$ & S-color & $\begin{array}{l}\text { Offset of segments } \& \text { color change } \\
\text { from all green to possibly } 1 \text { blue } \& \\
4-5 \text { red circles }\end{array}$ & S-onset & $\begin{array}{l}\text { With blue item } \\
\text { Without blue item }\end{array}$ & $\begin{array}{c}0 \mathrm{msec} \\
-8 \mathrm{msec}^{*}\end{array}$ \\
\hline $\begin{array}{l}\text { Wu \& Remington } \\
\text { (2003, Exp. 3) }\end{array}$ & S-color & $\begin{array}{l}\text { Offset of segments \& color change } \\
\text { from all blue to } 1 \text { green, possibly } \\
1 \text { blue \& } 4-5 \text { red circles }\end{array}$ & S-onset & $\begin{array}{l}\text { With blue item } \\
\text { Without blue item }\end{array}$ & $\begin{array}{l}\text { sig.* } \\
\text { sig.* }\end{array}$ \\
\hline $\begin{array}{l}\text { Wu \& Remington } \\
\text { (2003, Exp. 4) }\end{array}$ & S-color & $\begin{array}{l}\text { Color change from } 3 \text { blue \& } \\
3 \text { green circles to } 1 \text { green, possibly } \\
1 \text { blue \& } 4-5 \text { red circles }\end{array}$ & S-onset & $\begin{array}{l}\text { With blue item } \\
\text { Without blue item }\end{array}$ & $\begin{array}{l}\text { n.s. } \\
\text { n.s. }\end{array}$ \\
\hline
\end{tabular}

Note-The DCOH makes the correct prediction and the $\mathrm{CIOH}$ the incorrect prediction for experiments that obtained capture. In contrast, the DCOH makes the incorrect prediction, and the $\mathrm{CIOH}$ the correct prediction, for experiments that did not obtain capture. Under the Effect column, "sig." refers to a significant capture effect that was not reported, numerically, in that study, whereas "n.s." refers to a nonsignificant effect. "S" refers to singleton. $\quad{ }^{*} p<.05$ (two-tailed). ${ }^{* *} p<.05$ (one-tailed). $\quad{ }^{+}$The RT/Item slope is not different than $0.0 \mathrm{msec} /$ item, which suggests that attentional capture was obtained.

Table A4

Experiments in Which Both the DCOH and the CIOH Predict an Absence of Attentional Capture

\begin{tabular}{|c|c|c|c|c|c|}
\hline Experiment & Target & Target Display Features & Cue Feature & Miscellaneous & Effect \\
\hline \multicolumn{6}{|c|}{ Spatial Precuing Experiments } \\
\hline $\begin{array}{l}\text { Chastain \& Cheal } \\
\text { (1998, Exp. 3) }\end{array}$ & S-form & Onset of target display symbols & S-color & & n.s. \\
\hline $\begin{array}{l}\text { Chastain et al. } \\
\text { (2002, Exp. 1) }\end{array}$ & S-letter & Onset of $3 \mathrm{Xs} \& 1$ rotated C & S-orientation & & $.02 \mathrm{msec}^{*}$ \\
\hline $\begin{array}{l}\text { Chastain et al. } \\
\text { (2002, Exp. 2) }\end{array}$ & S-shape & Onset letters with S-shape & S-orientation & $100 \%$ invalid cue & sig.* \\
\hline $\begin{array}{l}\text { Folk et al. } \\
\qquad(1994, \text { Exp. 3) }\end{array}$ & S-motion & Onset of symbols with one in motion & S-color & & $-8 \mathrm{msec}$ \\
\hline $\begin{array}{l}\text { Gibson \& Amelio } \\
\quad(2000, \text { Exp. 1) }\end{array}$ & S-onset & $\begin{array}{l}\text { S-onset of target letter (target type was manipulated } \\
\text { between participants) }\end{array}$ & S-color & & n.s. \\
\hline $\begin{array}{l}\text { Gibson \& Amelio } \\
\quad(2000 \text {, Exp. 2) }\end{array}$ & S-onset & S-onset of target letter & S-color & & $0 \mathrm{msec}$ \\
\hline $\begin{array}{l}\text { Gibson \& Kelsey } \\
\quad(1998, \text { Exp. 2) }\end{array}$ & NL & Onset of white letters & S-color & & $7 \mathrm{msec}$ \\
\hline $\begin{array}{l}\text { Joseph \& Optican } \\
\quad(1996, \text { Exp. 1-2) }\end{array}$ & S-letter & Onset of segments to form letters & S-orientation & & sig. ${ }^{*}$ \\
\hline $\begin{array}{l}\text { Kim \& Cave } \\
\quad(1999, \text { Exp. 1) }\end{array}$ & S-onset & $\begin{array}{l}\text { S-onset of probe dot (on } 1 / 2 \text { of trials) following a dis- } \\
\text { play of } 3 \text { colored shapes }\end{array}$ & S-color & & sig.* \\
\hline $\begin{array}{l}\text { Kim \& Cave } \\
\quad(2001 \text {, Exp. 1) }\end{array}$ & S-onset & $\begin{array}{l}\text { S-onset of probe dot (on } 1 / 2 \text { of trials) following a dis- } \\
\text { play of } 3 \text { colored letters ( } 1 \text { was uniquely colored) }\end{array}$ & S-color & & sig.* \\
\hline
\end{tabular}




\begin{tabular}{|c|c|c|c|c|c|}
\hline \multicolumn{6}{|c|}{ APPENDIX (Continued) } \\
\hline Experiment & Target & Target Display Features & Cue Feature & Miscellaneous & Effect \\
\hline $\begin{array}{l}\text { Lamy \& Egeth } \\
\text { (2003, Exp. 1) }\end{array}$ & S-shape & Offset of segments to form shapes & S-color & & $25 \mathrm{msec}^{*}$ \\
\hline $\begin{array}{l}\text { Lamy \& Egeth } \\
\qquad(2003 \text {, Exp. 5-6) }\end{array}$ & Shape & $\begin{array}{l}\text { Offset of segments to form shapes with onset of tar- } \\
\text { get dots (no distractor on } 1 / 2 \text { of trials in Exp. } 6 \text { ) }\end{array}$ & S-color & $\begin{array}{l}\text { Exp. } 5 \\
\text { Exp. } 6\end{array}$ & $\begin{array}{l}-6 \mathrm{msec} \\
-41 \mathrm{msec}^{*}\end{array}$ \\
\hline $\begin{array}{l}\text { Pratt et al. } \\
\quad \text { (2001, Exp. 1) }\end{array}$ & S-onset & $\begin{array}{l}\text { S-onset of symbol target (cue-target combinations } \\
\text { were randomized or blocked) }\end{array}$ & S-color & $\begin{array}{l}\text { Random } \\
\text { Blocked }\end{array}$ & $\begin{array}{c}56 \mathrm{msec}^{*} \\
7 \mathrm{msec}\end{array}$ \\
\hline $\begin{array}{l}\text { Rauschenberger } \\
\quad(2003 \text { b, Exp. 1) }\end{array}$ & S-onset & Offset of segments to form letters, with target onset & S-luminance & & n.s. \\
\hline $\begin{array}{l}\text { Rauschenberger } \\
\quad(2003 \text { b, Exp. 2-3) }\end{array}$ & $\begin{array}{l}\text { S-luminance } \\
\text { transient }\end{array}$ & Offset of segments to form letters, with target onset & S-luminance & & n.s. \\
\hline $\begin{array}{l}\text { Richard et al. } \\
\quad(2003 \text {, Exp. 4) }\end{array}$ & S-onset & S-onset of tilted line & S-color & & n.s. \\
\hline $\begin{array}{l}\text { Richard et al. } \\
\quad(2003 \text {, Exp. 5) }\end{array}$ & S-onset & S-onset of tilted line (SOA 100 or $200 \mathrm{msec}$ ) & S-color & & n.s. \\
\hline \multicolumn{6}{|c|}{ Irrelevant Singleton Experiments } \\
\hline \multicolumn{6}{|c|}{ No irrelevant singleton experiments fall within Cell IV. } \\
\hline \multicolumn{6}{|c|}{ Distractor Interference Experiments } \\
\hline \multicolumn{6}{|c|}{ No distractor interference experiments fall within Cell IV. } \\
\hline
\end{tabular}

(Manuscript received January 11, 2006;

revision accepted for publication September 5, 2006.) 